\title{
Terror in the Justice System: Effects of Defendant Race and Religion on Juror Decision-Making in a Criminal Trial
}

\author{
by
}

Andrew Woodard

A thesis submitted to the Faculty of Graduate and Postdoctoral Affairs in partial fulfillment of the requirements for the degree of

Master of Arts

in

Psychology

Carleton University

Ottawa, Ontario

(C)2018

Andrew Woodard 


\section{Abstract}

New Canadian anti-terror legislation was passed in 2015, expanding the scope of criminal offences to include advocating or promoting terrorism offences in general. This study explored juror perceptions of the applicability of this law by having participants read a trial transcript involving this charge in which the defendant's race (Black/White/Arab) and religion (Christian/Muslim/undisclosed) were manipulated. Participants provided a guilty/not guilty verdict, then answered a brief questionnaire on attributions of the defendant's actions and stereotypes held by the Canadian public. Results demonstrated that two attribution measures, defendant stability and defendant responsibility, were related to verdict outcome. Of note, at middling levels of defendant responsibility, the defendant's religion influenced verdict outcome, leading to more guilty verdicts for Muslim defendants. Furthermore, although defendant religion only showed a weak effect on verdict outcome, results indicated that this might operate via stereotypes of the defendant's religious group. Additionally, at some levels defendant stability and defendant responsibility were related to the strength of the effect produced by stereotypes of the defendant's religious group. Although White Canadians received lower stereotype ratings than Black or Arab Canadians, White defendants received more internal ratings of attribution than either Black or Arab defendants. Muslim Canadians received higher stereotype ratings than Christian Canadians and Canadians with no disclosed religion, and Muslim defendants' actions were perceived as less stable than Christian defendants or defendants with no disclosed religion. Finally, there was no direct effect of defendant race on verdicts. While no significant effect was found of racial bias, the results demonstrate important biases that may influence juror decisionmaking in anti-terrorism trials. 


\section{Acknowledgements}

Most deservedly, I will begin with a heartfelt thank you to Dr. Evelyn Maeder. The success of this project has relied utterly on her support, assistance, and amazing patience. She has been nothing short of a phenomenal presence through my years at Carleton University. I would also like to thank Dr. Craig LethSteensen and Dr. Andrew Smith, whose assistance in plotting the statistical analyses present in this project was exemplary. Lastly, I would like to thank each and every member of the Legal Decision-Making Lab, who have taught me much in our meetings, and whose company made the journey all the better. 


\section{Contents}

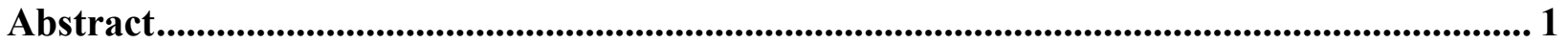

Acknowledgements ............................................................................................................. 2

Terror in the Justice System: Effects of Defendant Race and Religion on Juror DecisionMaking in a Criminal Trial...............................................................................................................5

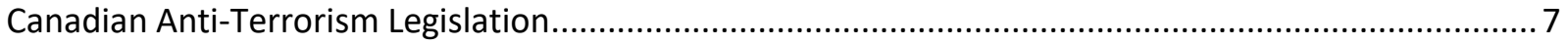

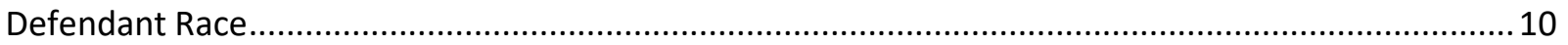

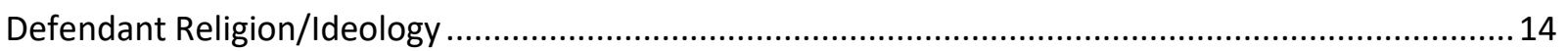

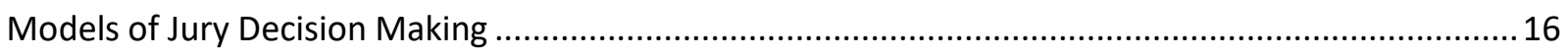

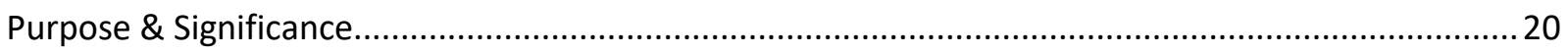

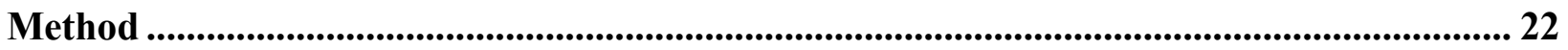

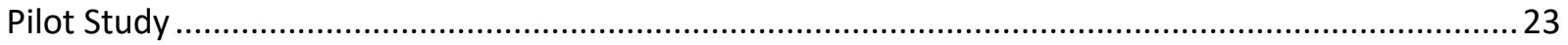

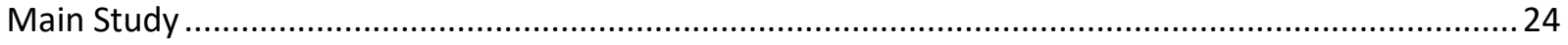

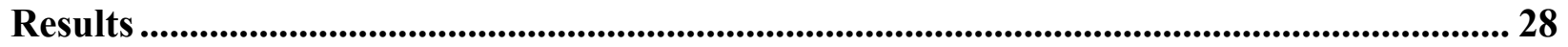

Verdict Outcome

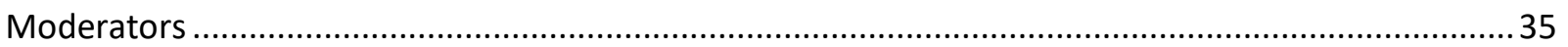

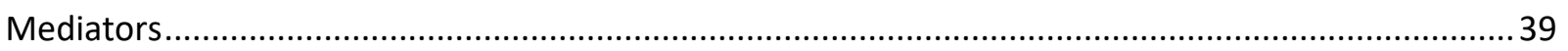

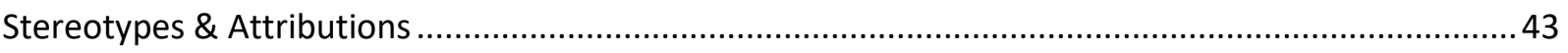

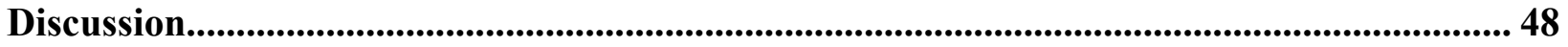

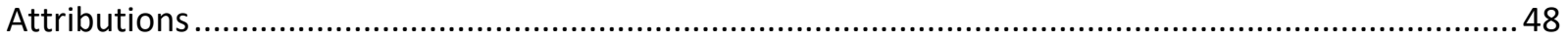

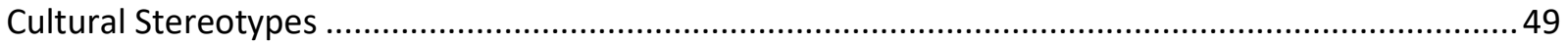

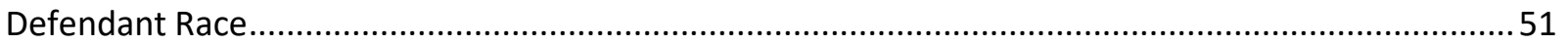

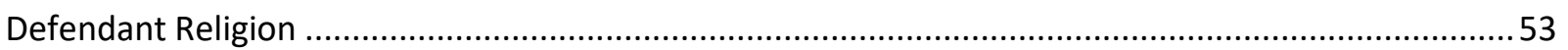

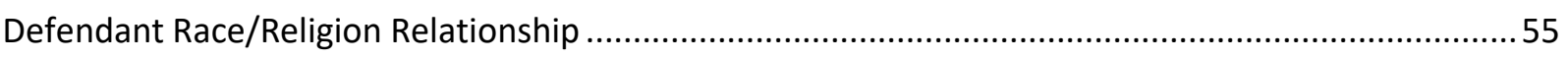

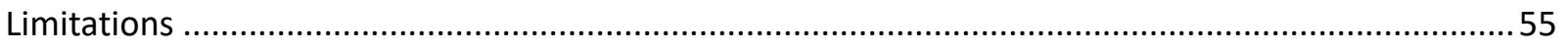

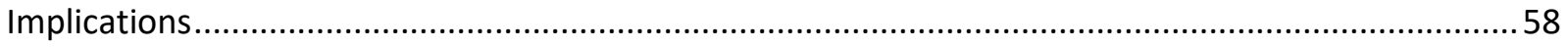

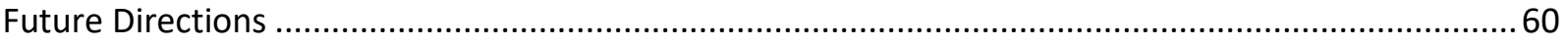

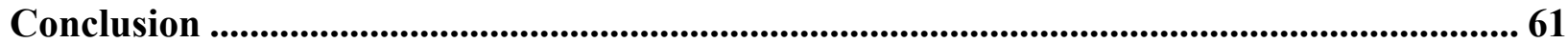

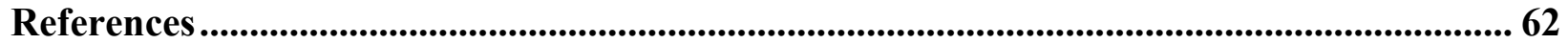

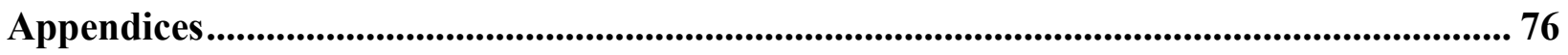

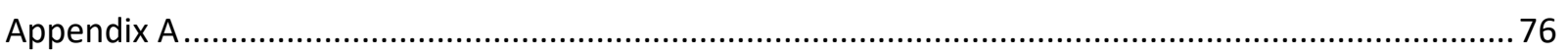

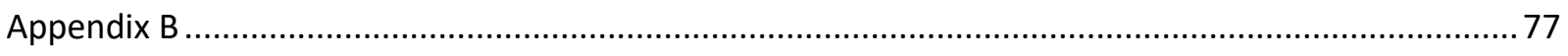

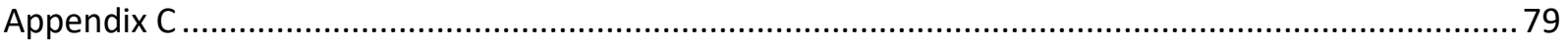




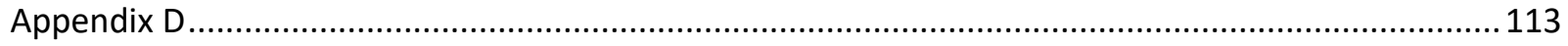

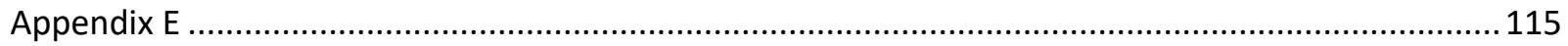

Appendix F …

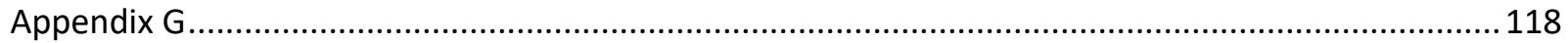

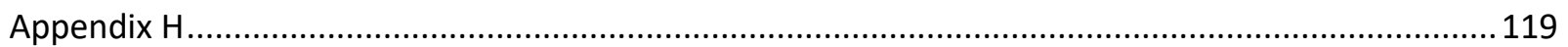

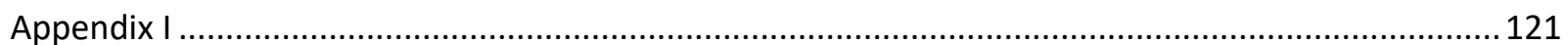




\section{Terror in the Justice System: Effects of Defendant Race and Religion on Juror Decision- Making in a Criminal Trial}

As the $21^{\text {st }}$ century progresses, the threat of terrorism continues to play a prominent role in the public and media's attention. Canada's anti-terrorism laws were initially formed in direct response to the September $11^{\text {th }}$ attacks, creating a series of broad criminal offences and granting new authorities to government institutions. There has been debate since their inception over whether these laws were a necessary extension to the Justice System (Bahdi, 2003); further, they have faced significant criticism for their potential to be misused (Morgan, 2011; Tator, 2006). Recently, the Canadian government has passed Bill C-51, the Canadian Anti-Terrorism Act (2015), to further expand these authorities. The Canadian Bar Association, the largest professional association of lawyers in Canada, identified in their Executive Summary on Bill C51 how the poor wording of these bills could have failed to "[...] strike the appropriate balance between enhancing state powers to manage risk and safeguarding citizens' privacy rights and personal freedoms $[\ldots]$ ", potentially leading to their abuse. Other critics have stressed that the vagueness of the language introduces the danger of infringing upon freedom of speech in civil and academic settings (Canadian Association of University Teachers, 2015). Furthermore, researchers have yet to begin to investigate how these laws, now fully implemented, might be applied once they make their way to court. An important avenue of research in this domain is the study of jurors, and juror decision-making, and this will be the focus of my study.

Juries' decisions are used to determine guilt (or lack thereof) of defendants for our most serious crimes; given the importance these legal decisions have in our society, it is critical to understand how they are applied. Extra-legal factors are influences on jurors that have no relevance to the court case, and a wide range of them have been examined in jurors, though 
much of the research has been conducted in the United States. Characteristics such as race have been shown to influence the way jurors view the credibility and weight of testimony provided on the stand (Maeder \& Hunt, 2011). As an example, the theory of aversive racism (Gaertner, \& Dovidio, 1986) describes how individuals continue to possess negative stereotypes of other racial groups, despite removing most of their overtly racist behaviours. The individuals then begin to avoid contact with the racial group, limiting future exposure. These negative stereotypes can lead to discriminatory behaviour, specifically when individuals find themselves in ambiguous situations with little information to rely on other than their previous misconceptions (Gaertner, \& Dovidio, 1986). Following from this, aversive racism has been shown to impact how those individuals evaluate members of other groups, which has potential ramifications for juries (Dovidio, \& Gaertner, 2004; Feagin, \& Feagin, 1978). Factors such as age (Higgins, Heath \& Grannemann, 2007; Tang \& Nunez, 2003) and gender (Duke \& Desforges, 2007; Thompson, Merrifield, \& Chinnery, 2011) of mock jurors and defendants have been shown to play a role in decisions, affecting perceptions of accuracy, truthfulness, and believability of testimony (Pozzulo, Dempsey, Maeder, \& Allen, 2010). Similar research would be beneficial to understand extra-legal factors in the context of anti-terrorism laws in Canadian courts.

The domain of anti-terrorism laws is relatively unexamined by research in Canada, despite the severity of the legislative response. It is my goal to look into recent Canadian anti-terrorism laws, examining the ways that they could be misused in a courtroom setting and how prospective jurors perceive the validity of their application. Legal scholars have suspected that these laws may not be fairly applied (Abell, 2015; Canadian Bar Association, 2015; Morgan, 2011), and here I look to apply an experimental approach that will provide additional evidence for expected outcomes. 


\section{Canadian Anti-Terrorism Legislation}

Canada's initial response to the call for anti-terrorism laws came in the form of Bill C-36, the Canadian Anti-Terrorism Act. Bill C-36 began its readings in October 2001, and was given royal assent by December of that year (Canadian Anti-Terrorism Act [C-36], 2001). Bill C-36 was considered an omnibus bill, containing measures for new powers of preventative arrest, investigative hearings, and an increased ability for the Attorney General to issue certificates preventing the disclosure of sensitive information. Furthermore, the bill created a body of terrorist groups to be defined by the Governor in Council, and established an official definition for terrorism and terrorist activity (Canadian Anti-Terrorism Act, 2001, c. C-36). The bill received serious debate and amendments in the House of Commons, and then passed within three months of its first reading (Roach, 2002, p. 145). Elements of the bill, such as the preventative arrests and new powers for investigative hearings, were limited with a five-year renewal clause. This clause was last debated in the House of Commons in 2013, where the passing of Bill S-7 successfully extended the provisions for another five-year term (Bahdi, 2003; Tator, 2006). A similarly timed piece of anti-terrorism legislation, the PATRIOT ACT from the United States, featured an anti-discrimination clause (USA PATRIOT Act, 2001, Title I, Sec. 102). However, no counterpart was included in Bill C-36, acting against the recommendations of legal scholars and a special Senate committee at the time. The bill was passed with controversy, as a number of legal experts and members of parliament argued that the new offences were already sufficiently covered under existing criminal law (Roach, 2002).

Bill C-51, the Anti-Terrorism Act, was given royal assent on June $18^{\text {th }}$, 2015. When the bill was initially raised in January, two recent acts of terrorism were cited by the Conservative 
Government as examples for the necessity of change in Canada's approach to anti-terrorism measures (Leblanc \& Hannay, 2015). The bill's reform of anti-terrorism laws broadly fell into five sections: (1) the Security of Canada Information Sharing Act, (2) the Secure Air Travel Act, (3) Criminal Code amendments, (4) Canadian Security Intelligence Service Act amendments, and (5) Immigration and Refugee Protection Act amendments. Of particular concern for my research is section 3, which adds the terrorism offence S. 83.221 to the criminal code, which reads as follows:

Every person who, by communicating statements, knowingly advocates, or promotes the commission of terrorism offences in general — other than an offence under this sectionwhile knowing that any of those offences will be committed or being reckless as to whether any of those offences may be committed, as a result of such communication, is guilty of an indictable offence and is liable to imprisonment for a term of not more than five years.

(Criminal Code, 2015, s 83.221)

\section{Ambiguity in the Law}

The Canadian Association of University Teachers (2015) has raised concerns about the breadth of this new offence in the academic setting. This new legislation has no statutory defences, such as public or educational interest, that might provide a clear delineation between criminal activity and legal or educational consideration of terrorism. The CAUT suggested that the vagueness of the language allows s. 83.221 to potentially limit professors in discussing terrorism even hypothetically due to the lack of these defences. Similarly, the unclear wording of the law was noted by Forcese and Roach (2015) to be problematic, as it made it difficult to understand what type of actions were being outlawed. Outside of academic settings, concerns have been raised with basic freedom of speech, characterizing the intent of the law to cast a wide 
and loose net, with insufficient care given to civil liberties (Canadian Bar Association, 2015; Leblance \& Hannay, 2015; Organization for Security and Co-operation in Europe, 2015; Ruby \& Hasan, 2015). As Forcese and Roach (2015, p. 1) noted, "The scope of the new offence is not clear and the offence is sweeping in its criminalization of advocacy and promotion of 'terrorism offences in general', because terrorism offences themselves are sweeping."

The broad applicability of this law and its vague terminology raise the question of how it will be used in a practical sense in our legal system. The RCMP has already created internal documents that acknowledge environmental activists as potentially falling under the extensive scope of this offence (RCMP, 2014). Given the broadness of this new law, some concern arises for how consistently actors in the justice system will perform. In some cases, jurors will be given the unenviable job of determining the guilt of defendants, weighing whether the law is applicable for a crime they have little knowledge of. It is the legal system's obligation to ensure that these decisions are consistent and unbiased, and past research has shown a lack of information or clear instructions, such as a vague law, may lead jurors to rely on factors other than strictly the evidence at hand (Pfeifer \& Bernstein, 2003).

In Canada juries are utilized in our most serious criminal cases, generally dealing with offences that include a prison sentence of over five years, or an indictable offense, though some exceptions allow for juries in other conditions (Canadian Department of Justice, 2016). In these proceedings, the jury is composed of 12 individuals selected from the province or territory in which the trial is held. Jury research as a topic began in the United States, which due to population, propensity, and a broader range of applicable charges have considerably more jury cases than Canada. Jury research saw its roots early in $20^{\text {th }}$ century with judges taking it upon themselves to record how often their personal appraisal of cases aligned with what the sitting 
jury decided. In the 1950's researchers began to see more methodical assessment of jury decision-making beginning at the University of Chicago, and interest in the topic has steadily grown since then (Devine, 2012). The 90's produced a series of meta-analyses, which gave a more comprehensive understanding of the field to researchers (Mazzella \& Feingold, 1994; Narby, Cutler \& Morgan, 1993; Sweeney \& Haney, 1992), and in the 2000's there has been a rapid expansion of research in the domain (Devine, 2012).

\section{Defendant Race}

Racial effects have been a common topic in the jury decision making literature, with extensive research in the United States looking at Black and White defendants and victims. Overviews of the field have yielded some conflicting results in the past. Recent meta-analyses have found a small effect for out-group race; jurors provide more guilty verdicts when evaluating a defendant of a race that differs from their own (Devine, \& Caughlin, 2014; Mitchell, Haw, Pfeifer, \& Meissner, 2005). Past research has suggested Black defendants receive more severe punishments than White defendants (Johnson et al., 2002; Sweeney \& Haney, 1992), but some studies have failed to replicate this effect, or found results suggesting the opposite outcome (Marcus-Newhall, Blake, \& Baumann, 2002; Mazzella \& Feingold, 1994). In the Canadian context, research concerning racial groups such as Aboriginal and Arab defendants and victims has been less thorough, though some examples exist. Research has shown that when defendant and victim race are manipulated in a sexual assault case, the participants rated defendants as more guilty on a 7 point scale of subjective guilt when the defendant was Aboriginal Canadian as opposed to White Canadian (Pfeifer \& Ogloff, 2003). Furthermore, Aboriginal Canadian defendants receive harsher sentence recommendations than White or Black defendants (Maeder, Yamamoto, \& Saliba, 2015). In Canada, there has been some examination of which stereotypes 
exist (Corenblum \& Stephan, 2001), how they might influence juror decision making (Maeder, Yamamoto, McManus \& Capaldi, 2016), and how race salience moderates this effect (Maeder, Yamamoto \& McManus, 2015), but this research is relatively new and only beginning to broach this topic. I have relied on a broader review taken from similar literature on how attributions and stereotypes affect minority groups to bolster this.

Aversive Racism. As briefly described above, the theory of aversive racism explores how individuals continue to maintain negative stereotypes about a racial group. It discusses how social pressure may curtail overtly racist behaviours, but leave behind attitudes that the individual may not be aware of (Gaertner, \& Dovidio, 1986). This impact on their evaluations comes from a reliance on stereotypes, and is stronger in ambiguous situations that lack other information to use in making decisions. Gaertner and Dovidio (1986) further explained that this influence on an individual's evaluations might lead to them beginning to avoid certain races, limiting their contact with the group, and affecting their behaviour when interacting with the group. Pfeifer and Bernstein (2003) examined this in a legal context by looking into how juror responses changed when the defendant's social status was ambiguous. When the defendant's social status (highly educated, employed, and with strong community ties) was described in detail, the effect of race was nonsignificant; however, lower social status defendants received worse dispositions as compared to high social status defendants. However, when no social status information was provided, Black defendants received dispositions similar to the low status defendants. Likewise, when participants were asked to guess the race of a racially-ambiguous defendant when information was provided on social status, participants linked high social status with White defendants, and low social status with Black defendants (Pfeifer \& Bernstein, 2003, pp. 756). To extend this, Pfeifer and Bernstein's second study investigated task specificity (jury 
instructions), and found similar results. When the ambiguity was removed from what the jurors were deciding on, race did not affect their decisions. However, when task specificity was reduced (no instructions or poor instructions), race became a relevant factor. This suggests that in low information environments, jurors rely more on stereotypes. In further studies, aversive racism has shown an impact in death penalty cases (Lynch \& Haney, 2009), and in scenarios where inadmissible DNA evidence produced ambiguity (Hodson, Hooper, Dovidio, \& Gaertner, 2005). In the context of the proposed study, the breadth of terrorism laws and inexperience jurors will have with them might create a similar situation, where there is ambiguity in how the laws are meant to be applied. Specifically, S.83.221 has been explicitly noted by legal scholars for being vague, and excessively broad (Canadian Bar Association, 2015; Forcese \& Roach, 2015). This may set the stage for the behaviours described by aversive racism theory, as applying S.83.221 in a court room setting may foster a low-information setting and encourage jurors to fall back on the stereotypes of race to inform their decision.

Stereotypes. Racial stereotypes are assumptions about an individual's behaviour or characteristics based on their perceived race, rather than any past knowledge of the individual (Fiske, 1998). Stereotypes are part of a triumvirate, tied with prejudice and discrimination, to explain racist or other bigoted behaviours. Firstly, stereotypes make up the cognitive component, beliefs that are often negative about a group of people. Secondly, prejudice is the affective component, which discusses the assessment of the members of a race or other group. Lastly, discrimination consists of the behavioural component, or the ways the individual changes how they act due to prejudice and stereotypes (Devine, 1989; Fiske, 1998). Research has shown that stereotypes and beliefs can influence how information is processed and remembered (Erber \& Fiske, 1984; Shih, Pittinsky, \& Ambady, 1999; Smith \& Zarate, 1990). These stereotypes and 
prejudices have been shown to lead to interpersonal discrimination, or different treatment of some groups and their people as compared to other groups (Dovidio, Brigham, Johnson, \& Gaertner, 1996; Lott, \& Maluso, 1995). Given these effects, stereotypes can play an important role in the decisions jury members often face.

Studies in the United States show that the degree of information sought by mock jurors is reduced when racial stereotypes are associated with the crime in question (Jones \& Kaplan, 2003). In research this association has been referred to as 'race-crime congruency', and past studies have explored some of these race-crime links. In the United States Black individuals have been linked to blue collar crimes such as burglary, auto theft, and assault, and White people have been associated with white collar crimes like fraud, embezzlement, and counterfeiting (Gordon, Bindrim, McNicholas, \& Walden, 1988; Skorinko \& Spellman, 2013; Sunnafrank \& Fontes, 1983). When Ghavami (2013) examined perceived cultural stereotypes through free-response, he found some of the most common words/phrases associated with Arab Americans were Terrorists, Oppress Women, Dark Skinned, Muslim, and Dangerous. In the Canadian context, the research on minority and crime stereotypes is limited and only shows modest evidence in support of racecrime congruency (Maeder et al., 2016). Unfortunately, previous research on what Canadian stereotypes exist of those who commit terrorism is absent. Current research has primarily focused on Aboriginal Canadians, and has suggested the public has mostly negative perceptions. Corenblum and Stephan (2001) found White Canadians perceived Aboriginal Canadians as stereotypically being aggressive, lazy, and poorly educated, and in Pfeifer and Ogloff's (2003) study examining mock jurors' ratings of guilt, they found stereotypes of Aboriginal Canadians as unintelligent, poor, dishonest, and irresponsible. The justice system has seen a substantial overrepresentation of Aboriginal Canadians in prisons, making up as many as 1 in 5 offenders 
currently incarcerated, despite making up only $4.9 \%$ of the population (Statistics Canada, NHS, 2017) and this overrepresentation in the prison system might be contributing to the negative perceptions. Criminal stereotypes associated with Arab individuals in Canada is less well understood. Maeder, Dempsey, and Pozzulo (2012) looked at how victims wearing burqa or hijab during testimony affected verdicts, and more broadly examined how defendant race impacted juror ratings of their reliability, truthfulness, accuracy, credibility, and believability. Here, Maeder, Dempsey, and Pozzulo (2012) found no racial effect on the credibility of Arab defendants when assessed by mock jurors. Additionally, some Arab Canadians have reported negative experiences in the wake of the September $11^{\text {th }}$ attacks (Chambers \& Roth, 2014; Hanniman, 2008), but it is difficult to be certain how this will translate to the courtroom setting. Research in other nations such as Australia have examined similar topics, finding strong connections between a fear of terrorism and increased conviction rates (Tait, 2011). This study will re-examine how race impacts mock juror decisions. It will target how Arab, Black, and White Canadians differ as defendants, an area currently suffering from a deficit of relevant research.

\section{Defendant Religion/Ideology}

The effects of defendant religion, and religious articles, in the courtroom has been examined in past research, albeit not directly investigating its relationship with anti-terrorism laws. In the Maeder, Dempsey, and Pozzolo (2012) study mentioned above, mock jurors were more likely to convict defendants if the victim testified wearing a veil, but unfortunately little more has been done to examine religious topics in Canadian courts. However, turning to studies in the United States yields several interesting effects, most common of which are the out-group bias effect, the similarity-leniency effect, and the black-sheep effect. Social Identity Theory (Tajfel \& Turner, 
1979) establishes a background for these effects; it discusses the tendency for individuals of social groups to favour their in-group against the out-group. This produces a better public appearance for the social group in question, and in turns improves the individual's self-image for being included in it (Tajfel \& Turner, 1986). In the courts, the out-group effect might arise when the majority of a jury differs from the defendant on characteristics such as religion or race, and yields a harsher appraisal of the defendant. The similarity-leniency theory follows similar if inverted lines, in cases with low to moderate evidence against the defendant, jurors will provide lower sentences and fewer guilty-verdicts for defendants who are similar to them in religious and racial characteristics (Kerr, Hymes, Anderson, \& Weathers, 1995). Furthermore, when mock jurors do rate defendants as guilty, they possessed less certainty in their verdicts when they perceived the defendants as more similar to themselves (Miller, Maskaly, Green, \& Peoples, 2011). This is not exclusively the case, however - the black-sheep effect occurs if jurors share a social group with the defendant, and yet they evaluate them more negatively (Marques, 1990). The black sheep effect can occur when the defendant's actions are so negative and evidence against them so compelling that they cast their shared social group in a poor light, leading to the juror rating them more harshly. Additionally, Miller et al. (2011) found deliberation reduced convictions of religious defendants, and argued this may be due to jurors being forced to provide reasons to justify their verdict choices to their fellow jurors.

Attributions. Attribution theory looks at how individuals explain the actions of those around them by categorizing how they assign responsibility for those actions (Fiske \& Taylor, 1991). The theory can illustrate how juror decisions could be influenced by the type of attribution they assume of the defendant (Weiner, 1986). In Heider's (1958) explanation individuals would assign, or attribute, responsibility for the behaviours they saw in others to internal or external 
factors. Internal factors can be causes such as personal characteristics, personality traits, or morality. External factors could be circumstances beyond the individual's control. In a criminal context attribution theory argues that an individual's explanation of what causes and motivates crime will affect their attitude towards punishment. Those who believe that crime can be explained by internal attributes such as personal choices or morality favour much harsher and more punitive responses to criminal activity and outcomes that support deterrence, and those who believe that crime is based in external attributes, such as necessity or extenuating social pressures, prefer rehabilitative sentencing (Templeton \& Hartnagel, 2012; Unnever, Cochran, Cullen, \& Applegate 2010; Unnever, Cullen, \& Jones 2008). Gordon et al. (1988) suggested that attributions could be a function of the typicality of the crime and race of the defendant. He found that in crimes with a prevalent stereotype linking them to a race, the defendant was given internal attributions when their race matched the racial-stereotype, and external attributions when it did not (Gordon 1990, Gordon \& Anderson, 1995). These effects are complex, and understanding how they might function inside of a jury setting requires modeling how jurors make decisions.

\section{Models of Jury Decision Making}

A number of theoretical models have been proposed to explain how juries come to their verdicts, and they vary greatly in concept. In the past, prescriptive Bayesian and Algebraic Models endeavored to weigh the individual points of evidence (Hastie, 1993), forming a structured linear approach to how much influence facts of the case should have on the final jury verdict. Some models incorporated group schemes to explain the influence of the social dynamics present in juries during the deliberation process (Devine, 2012, p. 21-23). I will focus on the more recent descriptive Story and Director's Cut Models, both of which attempt to include the contributions of the previous models into a broader picture. 
The Story Model. The Story Model supposes that as the trial proceeds the jury is actively engaged in building a mental narrative. The jurors attempt to form a coherent story of how the alleged crime played out, inserting evidence into this story as it is presented, or alternating the story to fit the new information (Pennington \& Hastie, 1992, p. 190). This process deviates sharply from the formulaic variants, as any mathematical modeling is absent in favour of examining how jurors verbally describe how they came to their decisions. In contrast, the Story Model incorporates how jurors rely heavily on their previous knowledge and beliefs, considering relevant stereotypes or attributes. In the Story Model juror decision making is divided into three categories: (1) jurors process relevant information in the court, creating one or more possible stories for how the alleged events took place, (2) jurors learn the legal requirements for each of their verdict decisions, and (3) jurors make a decision by matching their most appropriate story with the relevant verdict decision. Based on the facts, juries craft stories with linked chronological events, emphasizing causal and intentional relations between them.

In cases with difficult evidence, a number of possible stories are created and evaluated by members of the jury. The evaluation is based on four principles: coverage, coherence, uniqueness, and goodness-of-fit (Pennington \& Hastie, 1992, p. 189-191). The first two principles relate to how acceptable the juror will find the story. Coverage pertains to how much of the evidence presented in court is accounted for in the story. A story that uses all the facts presented to create a coherent narrative would have very good Coverage, and contribute to the juror having high confidence if that story was selected. Coherence is further divided into three subgroups: consistency, plausibility, and completeness. Consistency is the degree that the story avoids contradictions in its internal logic; plausibility relates to how well the story fits with preconceived notions the juror might have of how similar events occur; and completeness 
addresses the extent to which the story forms a continuous casual narrative, without any missing 'scenes' or unexplained questions. A high Coverage and Coherence creates a story that is very acceptable to jurors for potential selection, but when there are multiple stories that have similar levels of acceptance this creates a low degree of Uniqueness. Uniqueness suffers when there are multiple competing stories, and jurors' confidence in their selection follows, as it becomes less certain that the story they selected was what truly occurred. Goodness of Fit relates to how well the chosen story matches the legal verdict categories for the case, and the degree of fit also contributes to juror confidence in their final selection (Pennington \& Hastie, 1992, pp. 189-192, Devine, 2012, pp. 27-29). This presents a sound explanation of how individual jurors make sense of court cases, and it neatly describes the processes shown when jurors verbally described their thoughts as they took in case facts. However, the Story Model is limited in the attention given to jurors' previous biases, such as the attributions or stereotypes outlined above.

The Director's Cut Model. In contrast, the Director's Cut Model of jury decision making uses the narrative-centric approach to how jurors choose verdicts, but with a greater emphasis on how jurors are influenced by pre-trial information and extra-legal factors. As discussed in Devine's Jury Decision Making: The State of the Science (2012), the Director's Cut Model is one of the two components of the broader Integrated Multi-Level Theory of Jury Decision Making. The other half is the Story Sampling Model, which handles jury deliberation post trial. For simplicity, the Director's Cut Model can be broken into three sections, (1) the influences a juror carries into court pre-trial, a 'shooting script' of assumptions and biases; (2) a categorization of the influences as the prosecution builds a story and the defence creates an alternate, or contends with validity of the first; and (3) the cumulative post-trial story status of these factors. 
The first section examines jurors as they enter the trial, categorizing influences they possess upon arrival into four groups: the case, defendant characteristics, juror characteristics, and the narrative. The influences in the case consist of pre-trial media exposure, the number of charges against the defendant, and the seriousness of the charges. The defendant's characteristics include socio-economic status, criminal record, attractiveness, and demeanor. The juror's relevant characteristics are race, gender, socio-economic status, and trust in the legal system. Lastly, the narrative is initially established by the opening statements of the prosecution and defence. Following the tendency of jurors to think of case information in a narrative context, the prosecution is highly motivated to create a sequence of alleged events that they will then strive to prove through the course of the case.

The second section pertains to the prosecution and defence, and how their arguments might prove influential on the juror's representation/story. The influences in the prosecution's arguments consist of scope, credibility, and singularity. Scope relates to the sophistication of the evidence, or the extent that it describes the actions taken and the mindset of the individuals taking those actions, or how much of the narrative the evidence explains. Credibility covers the degree that the juror trusts the evidence, and the model assumes evidence will be considered credible unless it is violating one of three terms: (1) the evidence is presented by an inconsistent witness, (2) the evidence is inconsistent with how the juror believes the world works, or (3) the evidence is disputed by one or more other credible actors during the trial. Singularity concerns how well the evidence presented asserts one story is correct. As discussed in the Story Model, having multiple stories, even if they are all well supported, has a negative effect on juror confidence in their selection. For the defence, the arguments are rooted in either providing an alternative story for the jury, or attempting to undermine the prosecution's story. Arguments 
involving alternative stories can be categorized as (1) wrong defendant, (2) wrong actions, (3) wrong mindset, or (4) wrong consequences, and all serve to either reduce or remove the defendant's culpability for the crime. In contrast, undermining the prosecution's story involves arguments that do not present a possible alternative, but either suggest the current story is incorrect on too many salient details, or insufficient legally to convict. This leads into the last section, post-trial story status, which involves a consideration of the previous arguments waged, through a lens of the biases the juror possesses. This creates the representation, or story, the juror will bring into deliberation.

The Director's Cut and Story Models create a framework that provides the context for how the other influences on juror decision-making discussed above will ultimately change verdicts. Prospective jurors may have a pre-conceived idea of how terrorism operates, and what it looks like, long before they ever enter a court or are presented with the facts of a case. Devine's Director's Cut Model will provide the substance of several of my hypotheses in the present research - explaining the differences in mock jurors' verdicts and their appraisal of the terrorism charge.

\section{Purpose \& Significance}

The goal of the current research is to better understand how jurors might perceive the applicability of recent terrorism legislation. The models of jury decision making explained above inform us how jurors assess the complex information in a courtroom, and this relates to how they might perceive the application of laws in differing ways. The emphasis on stereotypes, narratives, and biases in these models speaks to the potential for jurors to have differing individual views of such a broad criminal offence, varying based on characteristics of the defendant, themselves, and the crime. The purpose of this research was to investigate the 
relationship between defendant race, defendant religion, and S. 83.221, Promoting or Advocating for the Commission of Terrorism Offences. In particular, I examined how defendant race and defendant ideology would interact with verdict outcomes, stereotypes, and attributions.

Furthermore, I hoped to determine if defendants of a particular race, ideology, or a combination of the two would receive more guilty verdicts than other combinations defendants, and if this change in verdicts could be explained by a relationship with publicly held stereotypes of those groups.

\section{Hypothesis \#1: Defendant Race}

Research has shown that in situations with low information, or ambiguity in guidelines, jurors will rely on pre-conceived notions to help make their decisions (Pfeifer \& Bernstein, 2003). Furthermore, similarity-leniency theory suggests that participants will rate defendants of the same race less harshly, and I anticipated a predominantly White sample following Canadian demographics (Statistics Canada, NHS, 2017). I predicted that the effects of race, and the negative stereotypes that exist for Black and Arab Canadians, would produce more guilty verdicts for defendants of those groups as compared to White defendants. In addition, there are several similar sub-hypotheses: I predicted the effects of race and similarity-leniency would yield A) more negative stereotype ratings, B) higher ratings of defendant responsibility, C) lower ratings of the stability of the defendant's behaviour, and D) higher ratings of internal attributions for Arab and Black Canadians than their White Canadian counterparts (Pfeifer \& Ogloff, 2003; Mitchell et al., 2005).

\section{Hypothesis \#2: Defendant Religion}

Similarly, I hypothesized that a similarity-leniency/out-group effect would produce more guilty verdicts for Muslim defendants than Christian defendants (Devine, \& Caughlin, 2014; 
Mitchell et al., 2005), or defendants with no disclosed religion. As above, sub-hypotheses follow as: I predicted that a similarity-leniency/out-group effect would yield A) more negative stereotypes, B) higher ratings of defendant responsibility, C) lower ratings of the stability of the defendant's behaviour, and D) higher ratings of internal attributions for Muslim defendants than Christian defendants or defendants with no disclosed religion.

\section{Hypothesis \#3: Defendant Race/Defendant Religion Interaction}

The Director's Cut model of jury decision-making proposes that jurors form a sequence of events suggested by the evidence presented in court, and determine guilt based on which narrative (guilty or not guilty) seems most coherent and plausible (Devine, 2012). I predicted that trial transcripts where the defendant race and ideology mirror past well known terrorist stereotypes, such as Arab defendants with Islamic religious ideology, would lead to more guilty verdicts than other combinations of defendant race and defendant religion (Devine, 2014; Pennington \& Hastie, 1988). As previously, I also predicted Arab defendants with Islamic religious ideology would yield A) higher ratings of defendant responsibility, B) lower ratings of the stability of the defendant's behaviour, and C) higher ratings of internal attribution than other combinations of defendant race and defendant religion (Devine, 2014; Pennington \& Hastie, 1988).

\section{Method}

To facilitate the main study, a pilot was conducted. The goal of this pilot study was to address the concern that the actions described in the scenario would have resulted in the defendant being viewed as either predominantly guilty or not guilty, leading to ceiling or floor effects. To examine this, the pilot study tested the different scenarios (absent manipulations of race or religion), to ensure that they did not produce outcomes where the participants only found 
the defendant guilty or not guilty, and then selected the scenario with the most even divide of verdict outcomes for use in the main study.

\section{Pilot Study}

Participants. Participants were recruited via Qualtrics. To establish that all participants were eligible for jury duty, they were given a brief questionnaire covering the most common ways to be excluded from the juror pool. As per juror requirements, all participants were required to be at least 18 years old, reside in Canada, have no previous indictable offence on record, and possess Canadian citizenship. Sixty total participants were recruited, with 20 participants in each scenario.

\section{Materials.}

Screening forms. As mentioned, participants were provided with a basic screening form to assess their eligibility as a Canadian juror. The screening form included questions on participant age, past indictable convictions, Canadian residency, and citizenship.

Juror instructions. Prior to being provided with the trial transcript, participants were given a set of jury instructions. The instructions include an explanation of the burden of proof, the standard of reasonable doubt (National Judicial Council, 2011), and S 83.221 of the Canadian Criminal Code. The instructions were created following guidelines provided by the National Judicial Council of Canada for judges' use in the courtroom.

Trial transcript. Participants read a trial transcript wherein the defendant is charged with S 83.221 of the Canadian Criminal Code, Advocating or Promoting the Commission of Terrorism Offences. The trial transcript describes an ideologically motivated speaker advocating for civil disruption. The degree of disruption advocated for was manipulated. Three scenarios 
were used to provide the differing levels of severity for this disruption. In the 'Unspecified Action' condition, participants read a scenario involving the defendant advocating for an unspecified action to a group of peaceful protestors outside of a government building. In the 'Forming Militias' condition, participants read a scenario involving the defendant advocating for the formation of militias through individuals arming themselves and stockpiling resources. In the 'Riot' condition, participants read a scenario involving the defendant advocating for peaceful protestors to take to the streets and riot. In the pilot transcript, defendant race and defendant religion were not made explicit.

Juror questionnaire. Following the trial transcript, participants made a dichotomous guilty/not guilty verdict decision concerning the defendant with regards to Advocating or Promoting the Commission of Terrorism Offences.

Results. The verdict results of each condition were examined individually with frequency tables of conviction outcomes to select the scenario with the most even divide of guilt/not guilty verdicts. The 'Forming Militias' condition yielded the most even distribution of verdicts (33\% Guilty, $66 \%$ Not Guilty), and was therefore used for the main study.

\section{Main Study}

Participants. A G-power analysis indicated that 447 participants were needed for the main study to attain a power level of .80 for logistic regression using a 3 by 3 factorial design (Faul, Erdfelder, Buchner, \& Land, 2009), which falls near conventional recommendations of 50 participants per cell (450). Recruitment of a national sample of Canadian participants was conducted through Qualtrics Panels; participants were paid $\$ 5$ as compensation. Qualtrics collected basic demographic information of the participants. Qualtrics provided a small number 
of additional participants, resulting in a total count of 455 participants for analysis. All of the final participants $(\mathrm{N}=455)$ passed screening and manipulation checks, indicating they were eligible for jury duty. All participants were at least 18 years old, understood written English, had no prior indictable offenses, and were a Canadian Citizen currently residing in the country. Of the participants that responded to demographic questions $(\mathrm{N}=399)$, ages ranged from 18 to 85 years old $(M=45.73, S D=15.40)$. Participant gender was divided by $254(55.8 \%)$ women, 197 $(43.3 \%)$ men, $1(.2 \%)$ trans individual, and 1 reporting another gender identity $(.2 \%)$. Participant race information reported at 371 (81.5\%) White, 23 South Asian (5.1\%), 17 Indigenous (3.7\%), 9 Black (2.0\%), 9 West Asian (2.0\%), and 26 other (5.6\%). Participant religious information reported to be 104 Catholic (22.9\%), 130 other Christian (28.6\%), 175 Non-Religious (38.5\%), 6 Islamic (1.3\%), 6 Buddhist (1.3\%), 7 Judaism (1.5\%), 1 Sikh (.2\%), and 26 reporting other $(5.7 \%)$.

\section{Materials.}

Juror instructions and screening forms. The juror instructions and screening forms were identical to those used in the pilot study described above.

Trial transcript. Participants read one of 6 versions of a trial transcript. Defendant race (Arab, Black, White) and defendant religion (Christian, Muslim, No Religion) were manipulated in each transcript. Participants read a scenario involving the defendant advocating for the formation of militias through individuals arming themselves and stockpiling resources. In the pilot $(N=30)$ this transcript demonstrated the most even split of verdict outcomes $(66 \%$ Not Guilty, 34\% Guilty) in the absence of race and religion manipulations. The race of the defendant was manipulated by varying a colour photograph included in the transcript and the name of the defendant. These photographs were tested in a separate pilot study $(N=30)$ to match for 
perceived age, attractiveness, and likeability. The religion of the defendant was manipulated in the text of the scenario, describing the organization the defendant was protesting alongside as either A) a Muslim University Students Association, B) a Christian University Students Association, or simply C) a University Students Association.

Juror questionnaire. Participants were asked to make a guilty/not guilty verdict decision with regards to Advocating or Promoting the Commission of Terrorism Offences. After the verdict outcome is decided, participants were presented with a modified version of Jones and Kaplan's (2003) attribution measure, a checklist questioning the participants on what they perceive to be the cause of the defendant's actions. Additionally, participants were provided with a cultural criminality stereotype checklist. The checklist was produced by Maeder and McManus (accepted), and is a heavily modified and reduced version of the Katz and Braly (1933) list of ethnic stereotypes, with additional terms added based on the work of Devine and Elliot (1995) and Flemming (2006). Maeder and McManus formed their list of adjectives by having three independent coders select terms for being positively related to criminality (adjectives that imply criminality), negatively related to criminality (adjectives that imply a lack of criminality), and unrelated to criminality (no association). Maeder and McManus showed inter-rater reliability with kappa coefficients ranging from .78 to 1.00 between the coders, and the final list retained 19 total criminality-related adjectives (Appendix E). Participants selected a value between 1 (not at all) and 7 (very much) to assess the degree that each criminality-related word represents the stereotype Canadians hold for a given group. Participants were requested to fill out one checklist for stereotypes relating to the defendant's race, and a second checklist for stereotypes relating to the defendant's religion. The decision to use cultural stereotypes over personal stereotypes was intended to mitigate the inherit bias that exists in self-reporting explicit personal stereotypes 
(Aberson, Shoemaker, \& Tomolillo, 2004; Brauer, Wasel, \& Niedenthal, 2000). Lastly, manipulation and attention checks were included to gauge how attentive the participant was while reading the transcript. Participants were questioned about the race, name, and religion of the defendant, and the type of charge laid against them (Appendix G).

Procedure. Qualtrics Panels was used to recruit the participants for this study. Qualtrics is a crowd-sourcing company that produces panels of participants based on requested characteristics. Qualtrics provides an online platform for potential participants to select studies they are interested in, if they meet the requirements of the panel. For this study, participants were initially only informed that the study involves jury decision-making. Once participants provided their informed consent, they were screened using the form described above relating to juror eligibility (Appendix A). Participants that failed to meet the requirements of jury eligibility were removed at this stage, and informed as to why. Eligible participants were randomly assigned to one of the 6 conditions of trial transcript, and then provided with juror instructions. Following their review of the transcript, participants were given the brief questionnaire relating to guilty/not guilty verdict outcomes, attributions, cultural racial stereotypes, cultural religious stereotypes, and attention checks. Upon completion, the participants were debriefed on the purpose of the study.

Design. A 3 [Defendant race: White/Arab/Black] x 3 [Defendant religion: Christian/Muslim/Non-religious] factorial design was implemented in this study. 


\section{Results}

Responses to the Cultural Criminality Checklists (for both defendant race and religion) and attribution scales were examined to test the full set of hypotheses. Participants received a Criminality Checklist for the defendant's race, and another for the defendant's religion. After reverse-coding where appropriate, participant ratings for the Cultural Criminality Checklists were considered with Cronbach's alpha to determine if the items could be combined to form a stereotype measure for each group. The Cronbach alphas all exceeded the recommended threshold of .7 (Kaplan \& Saccuzzo, 1982), with the White CCC yielding .86, Black CCC .84, Arab CCC .85, Muslim CCC .86, Christian CCC .81, and Canadian CCC .81. To examine the data prior to analyses, the Criminality Checklists for all racial and religious groups were examined for outliers with z-scores and boxplots. No outliers or substantial skew was found in the White CCC scores, Black CCC scores, or Arab CCC scores. Religion CCC scores showed some outliers, however none were extreme for Muslim CCC scores, or Christian CCC scores. The Canadian CCC produced a mild positive skew, and had three extreme outliers. However, the data were examined with and without these outliers and showed equivalent results, and analyses retained outliers so as to not unnecessarily reduce the sample size.

The attribution measure consists of three scales, as in Jones and Kaplan (2003): defendant internality, defendant stability, and defendant responsibility. Participant ratings for each of the attribution subscales were analyzed with Cronbach's alpha to examine their internal consistency. The Cronbach's alphas all exceeded or fell near the recommended threshold of .7, with defendant internality yielding .78, defendant stability showing .86, and lastly defendant responsibility producing a score of .68. To account for the potential for multicollinearity, the CCC and attribution variables were centered prior to analyses involving interactions. The normality of all 
continuous predictors was assessed with the simple examination of Q-Q plots and histograms, and all appeared normal upon visual inspection.

Table 1 - Summary of verdict decisions for Advocating or Promoting charge by defendant race and defendant religion.

\begin{tabular}{llcc} 
Defendant Race & Defendant Religion & \multicolumn{2}{l}{ Verdict Percentage by Condition } \\
\hline White & Christian & Not Guilty & Guilty \\
Black & Christian & $76.6 \%(46)$ & $23.3 \%(14)$ \\
Arab & Christian & $77.2 \%(44)$ & $22.8 \%(13)$ \\
White & Muslim & $72.2 \%(13)$ & $27.8 \%(5)$ \\
Black & Muslim & $68.8 \%(22)$ & $31.3 \%(10)$ \\
Arab & Muslim & $60.7 \%(37)$ & $39.3 \%(24)$ \\
White & Non-disclosed & $62.5 \%(35)$ & $37.5 \%(21)$ \\
Black & Non-disclosed & $71.9 \%(41)$ & $28.1 \%(16)$ \\
Arab & Non-Disclosed & $75.4 \%(43)$ & $24.6 \%(14)$ \\
\hline
\end{tabular}

\section{Verdict Outcome}

The study yielded a slightly lopsided split concerning verdict outcome, with $29.5 \%$ ( $n=$ 134) of participants selecting guilty, and $70.5 \%(n=321)$ choosing not guilty. A summary of verdict decisions by defendant race and defendant religion is presented in Table 1. To test hypothesis 1 (that Arab defendants and Black defendants would receive more guilty verdicts than White defendants), and hypothesis 2 (that Muslim defendants would receive more guilty verdicts than Christian or Non-disclosed defendants), verdicts were examined using a series of binary 
logistic regressions. To address the 3-level categorical variables of defendant race and defendant religion, analyses were run twice, with a differing reference variable each time. For the first set of analyses of defendant race I used White Defendants as the reference category (White $=0$, Black $=1, A r a b=1)$, and for defendant religion I used Non-disclosed religion for the reference category (Nondisclosed $=0$, Christian $=1$, Muslim $=1$ ). For the second set of analyses of defendant race I used Arab Defendants as the reference category, and for defendant religion I used Christian Defendants as the reference category. Table 2 presents the results of the first logistic regression analyses, which included all predictor variables to test whether defendant race, defendant religion, religion $\mathrm{CCC}$, race $\mathrm{CCC}$, defendant stability, defendant responsibility, or defendant internality predicted verdict outcome. In the first model, defendant stability $b=-$ $.83, p<.001$, and defendant responsibility $b=-.54, p<.001$, significantly predicted verdict outcome. A second model was run with the reference categories for Defendant Religion and Defendant Race exchanged to investigate differences between Christian and Muslim defendants, and Arab and Black defendants, respectively. No other predictor variables had a statistically significant loading when entered into the model, providing no support for hypotheses 1 or 2 . However, defendant religion, religion CCC, defendant stability, and defendant responsibility had a statistically significant effect on verdict outcome when outside of the model. Specifically, 1) Muslim defendants were found guilty more often than both Christian defendants and defendants with no disclosed religion, 2) higher participant ratings of stereotypes held by the Canadian public concerning the defendant's religion predicted more guilty verdicts, 3) participants more often found the defendant guilty when they rated the defendant as more likely to commit further crimes, or recommit the same offence, and 4) participants more often found the defendant guilty when they rated the defendant as more personally responsible for their actions. In contrast, 
defendant race showed no statistical significance in predicting verdict outcome inside the model or out, and was left out of further analyses.

Table 2 - Summary of model statistics for binary logistic regression predicting the effects of defendant race, defendant religion, race CCC, religious CCC, defendant stability, defendant responsibility, defendant internality on verdict outcome

\begin{tabular}{|c|c|c|c|c|}
\hline Predictor & $\boldsymbol{B}$ & $\overline{S E}$ & $e^{B}$ & Sig. \\
\hline \multicolumn{5}{|l|}{ White \& Non-disclosed Reference } \\
\hline Defendant Rel. (Christian) & -.35 & .32 & .71 & .275 \\
\hline Defendant Rel. (Muslim) & -.15 & .35 & .86 & .666 \\
\hline Defendant Race (Black) & .24 & .32 & 1.28 & .446 \\
\hline Defendant Race (Arab) & .228 & .36 & 1.26 & .521 \\
\hline Race CCC & -.01 & .15 & .91 & .496 \\
\hline Religious CCC & .19 & .13 & 1.22 & .147 \\
\hline Defendant Stability & $.83^{* * *}$ & .16 & 2.29 & .000 \\
\hline Defendant Internality & -.08 & .07 & .93 & .274 \\
\hline Defendant Responsibility & $.54^{* * *}$ & .10 & 1.71 & .000 \\
\hline \multicolumn{5}{|l|}{ Arab \& Christian Reference } \\
\hline Defendant Rel. (Muslim) & .20 & .37 & 1.22 & .592 \\
\hline Defendant Rel. (Non-disclosed) & .35 & .32 & 1.42 & .275 \\
\hline Defendant Race (White) & -.23 & .355 & .796 & .521 \\
\hline Defendant Race (Black) & .02 & .31 & 1.02 & .959 \\
\hline
\end{tabular}

Note. Set One refers to the logistic regression with White as the reference category for defendant race, and Nondisclosed as the reference category for defendant religion. Set Two refers to the logistic regression with Arab as the reference category for defendant race, and Muslim as the reference category for defendant religion. Race CCC, 
Religious CCC, Defendant Stability, Defendant Internality, and Defendant Responsibility were included in the second set, with no changes to results.

Defendant religion, religion CCC, defendant stability, and defendant responsibility were run in a new logistic regression to examine them for interaction effects. The five potential main effects (Dummy Coded Muslim Defendants, Dummy Coded Christian Defendants, religion CCC, defendant stability, defendant responsibility) were entered at the first block of the regression, followed by all two-way interactions into the second block. The model was run twice, first with the Non-disclosed religious category as reference, and second with the Muslim religious category as reference, and the results are presented in Tables 3 and 4. In the second model, defendant stability $b=-.84, p<.001$, and defendant responsibility $b=-.57, p<.001$, significantly predicted verdict outcome in the first block, and again in the second block. Specifically, defendants received more guilty verdicts when participants rated the defendant as more likely to commit further offenses or recommit the same offence, and when they rated the defendant as more personally responsible for the crime. The effects for Dummy Coded Muslim Defendants, Dummy Coded Christian Defendants, religion CCC, and all interactions failed to reach statistical significance on verdict outcome, and therefore no support was found for hypotheses 1 or 2 . 
Table 3 - Summary of model statistics for binary logistic regression predicting the effects of defendant religion, religious CCC, defendant stability, defendant responsibility, and interactions on verdict outcome.

\begin{tabular}{|c|c|c|c|c|}
\hline Predictor & $\boldsymbol{B}$ & $S E$ & $e^{B}$ & Sig. \\
\hline \multicolumn{5}{|l|}{ Step 1} \\
\hline Defendant Rel. (Christian) & -.34 & .32 & .71 & .275 \\
\hline Defendant Rel. (Muslim) & .08 & .34 & 1.08 & .815 \\
\hline Religious CCC & .11 & .13 & 1.12 & .378 \\
\hline Defendant Stability & .84 & .16 & 2.31 & $.000^{* * * *}$ \\
\hline Defendant Responsibility & .57 & .10 & 1.78 & $.000^{* * *}$ \\
\hline \multicolumn{5}{|l|}{ Step 2} \\
\hline Defendant Rel. (Christian) & -.27 & .39 & .77 & .49 \\
\hline Defendant Rel. (Muslim) & .30 & .37 & 1.35 & .42 \\
\hline Religious CCC & .31 & .22 & 1.37 & .15 \\
\hline Defendant Stability & 1.02 & .29 & 2.78 & $.000^{* * *}$ \\
\hline Defendant Responsibility & .80 & .19 & 2.23 & $.000^{* * *}$ \\
\hline Defendant Rel. (Christian) X Religious CCC & -.26 & .35 & .77 & .452 \\
\hline Defendant Rel. (Christian) X Defendant Stability & -.09 & .45 & .91 & .838 \\
\hline Defendant Rel. (Christian) X Defendant Responsibility & -.30 & .27 & .74 & .262 \\
\hline Defendant Rel. (Muslim) X Religious CCC & -.26 & .29 & .77 & .368 \\
\hline Defendant Rel. (Muslim) X Defendant Stability & -.36 & .38 & .70 & .334 \\
\hline Defendant Rel. (Muslim) X Defendant Responsibility & -.31 & .24 & .74 & .195 \\
\hline
\end{tabular}

Note. Defendant religion used Non-Disclosed as a reference category. 
Table 4 - Summary of model statistics for binary logistic regression predicting the effects of defendant religion, religious CCC, defendant stability, defendant responsibility, and interactions on verdict outcome.

\begin{tabular}{|c|c|c|c|c|}
\hline Predictor & $B$ & $S E$ & $e^{B}$ & Sig. \\
\hline \multicolumn{5}{|l|}{ Step 1} \\
\hline Defendant Rel. (Christian) & -.42 & .35 & .71 & .229 \\
\hline Defendant Rel. (Non-Disclosed) & -.08 & .34 & 1.08 & .815 \\
\hline Religious CCC & .11 & .13 & 1.12 & .378 \\
\hline Defendant Stability & $.84^{* * * *}$ & .16 & 2.31 & .000 \\
\hline Defendant Responsibility & $.57^{* * *}$ & .10 & 1.78 & .000 \\
\hline \multicolumn{5}{|l|}{ Step 2} \\
\hline Defendant Rel. (Christian) & -.57 & .40 & .57 & .151 \\
\hline Defendant Rel. (Non-Disclosed) & .30 & .37 & .74 & .42 \\
\hline Religious CCC & .05 & .19 & 1.06 & .771 \\
\hline Defendant Stability & $.66^{*}$ & .24 & 1.93 & .006 \\
\hline Defendant Responsibility & $.49^{* * *}$ & .14 & 1.64 & .001 \\
\hline Defendant Rel. (Christian) X Religious CCC & -.01 & .33 & .99 & .986 \\
\hline Defendant Rel. (Christian) X Defendant Stability & .27 & .42 & 1.31 & .515 \\
\hline Defendant Rel. (Christian) X Defendant Responsibility & .00 & .24 & 1.00 & .987 \\
\hline Defendant Rel. (Non-Disclosed) X Religious CCC & .26 & .29 & 1.29 & .368 \\
\hline Defendant Rel. (Non-Disclosed) X Defendant Stability & .36 & .38 & 1.44 & .334 \\
\hline Defendant Rel. (Non-Disclosed) X Defendant & .31 & .24 & 1.36 & .195 \\
\hline Responsibility & & & & \\
\hline
\end{tabular}

Note. Defendant religion used Muslim as a reference category. 


\section{Moderators}

To better understand possible interactions, defendant religion, religion $\mathrm{CCC}$, defendant stability, and defendant responsibility were then examined for potential moderation effects. Moderation was examined for defendant religion and religion CCC despite the absence of direct effects, as more recent research concerning mediation and moderation has highlighted the potential for these relationships to exist even without direct effects (Hayes, 2009; Hayes \& Rockwood, 2017). In the content of the current study, there is interest in further fleshing out the mechanisms behind juror decision-making, for which moderation may be pertinent. Defendant stability, defendant responsibility, and religion $\mathrm{CCC}$ were investigated with Hayes, A.F. PROCESS (2012). Hayes PROCESS runs a logistic model similar to those in Tables 3 and 4, but also presents the effect of the moderator at Low, Mean, and High levels, as shown below in Tables 5, 6, and 7. The moderator values for Low and High are fixed at one standard deviation below and above the mean respectively. Each model was run twice to exchange the reference category for defendant religion; the first analyses used Christian as a reference category, and the second used Non-disclosed as a reference category. The models were combined in the tables below. In the first model, the main effect of defendant stability on verdict outcome, $b=1.36, p<$ .001 , reached statistical significance. However, defendant stability was not found to moderate the effect for defendant religion at any level. In the second model, the effect of defendant religion on verdict outcome was moderated by average defendant responsibility $b=.75, p=.020$ at the mean, but failed to reach statistical significance for high or low levels of defendant responsibility. As such, Muslim defendants received more guilty verdicts than their counterparts, but only when participants' ratings for the defendant's personal responsibility were middling. In the third model, defendant religion and religion CCC's effects on verdict outcome failed to reach 
statistical significance, and the effect of defendant religion was not moderated at any level of religion $\mathrm{CCC}$.

The regression analysis provided some support for hypothesis 2 , as it showed that at some levels of defendant responsibility, defendant religion significantly predicted verdict outcome. However, the non-significant interaction between defendant religion and verdict outcome in all models, and lack of other statistically significant relationships, indicate that the support for hypothesis 2 is sparse.

Table 5 - Summary of model statistics for Hayes PROCESS Model 1, predicting the effects of defendant religion, and effect of moderation by defendant stability on verdict outcome.

\begin{tabular}{llllll}
\hline Predictor & $B$ & $S E$ & $\boldsymbol{z}$ & Sig.
\end{tabular}

\section{Logistic Regression Model}

Defendant Rel. (Muslim)

Defendant Rel. (Christian)

Defendant Stability

\section{Moderator Level Low}

Defendant Stability X Defendant Rel. (Muslim)

Defendant Stability X Defendant Rel. (Christian)

Defendant Stability X Defendant Rel. (MuslimB)

\section{Moderator Value At Mean}

Defendant Stability X Defendant Rel. (Muslim)

Defendant Stability X Defendant Rel. (Christian)

Defendant Stability X Defendant Rel. (MuslimB)

\section{Moderator Level High}

$\begin{array}{llll}.49 & .33 & 1.48 & .140 \\ -.30 & .32 & -.93 & .350 \\ 1.36 & .31 & 4.41 & .000\end{array}$

$\begin{array}{llll}.88 & .61 & 1.44 & .150\end{array}$

$\begin{array}{llll}-.32 & .61 & -.53 \quad .600\end{array}$

$\begin{array}{llll}.56 & .54 & 1.04 \quad .300\end{array}$

$\begin{array}{llll}.49 & .33 & 1.48 & .140 \\ -.30 & .32 & -.93 & .350 \\ .19 & .30 & .63 & .53\end{array}$




\begin{tabular}{lllll}
\hline Defendant Stability X Defendant Rel. (Muslim) & .09 & .39 & .24 & .810 \\
Defendant Stability X Defendant Rel. (Christian) & -.27 & .42 & -.65 & .520 \\
Defendant Stability X Defendant Rel. (MuslimB) & -.18 & .36 & -.51 & .611
\end{tabular}

Note. Non-disclosed Defendant religion was used as a reference category for Defendant Rel. (MuslimB) and Defendant Rel (Christian). Christian Defendant Religion was used as a reference category for Defendant Rel. (Muslim). Values for low and high moderator levels are -1 standard deviation from the mean for Low, and +1 standard deviation for High.

Table 6 - Summary of model statistics for Hayes PROCESS Model 1, predicting the effects of defendant religion, and effect of moderation by defendant responsibility on verdict outcome.

\begin{tabular}{|c|c|c|c|c|}
\hline Predictor & $\boldsymbol{B}$ & $S E$ & $z$ & Sig. \\
\hline \multicolumn{5}{|l|}{ Logistic Regression Model } \\
\hline Defendant Rel. (Muslim) & .745 & .32 & 2.33 & .020 \\
\hline Defendant Rel. (Christian) & -.22 & .33 & -.66 & .511 \\
\hline Defendant Responsibility & .79 & .172 & 4.58 & .000 \\
\hline \multicolumn{5}{|l|}{ Moderator Level Low } \\
\hline Defendant Responsibility X Defendant Rel. (Muslim) & 1.02 & .54 & 1.88 & .060 \\
\hline Defendant Responsibility X Defendant Rel. (Christian) & .07 & .60 & .12 & .911 \\
\hline Defendant Responsibility X Defendant Rel. (MuslimB) & 1.08 & .51 & 2.12 & .034 \\
\hline \multicolumn{5}{|l|}{ Moderator Level At Mean } \\
\hline Defendant Responsibility X Defendant Rel. (Muslim) & $.75^{* *}$ & .32 & 2.33 & .020 \\
\hline Defendant Responsibility X Defendant Rel. (Christian) & -.22 & .33 & -.66 & .511 \\
\hline Defendant Responsibility X Defendant Rel. (MuslimB) & .53 & .29 & 1.80 & .072 \\
\hline \multicolumn{5}{|l|}{ Moderator Level High } \\
\hline Defendant Responsibility X Defendant Rel. (Muslim) & .48 & .37 & 1.29 & .197 \\
\hline Defendant Responsibility X Defendant Rel. (Christian) & -.51 & .39 & -1.31 & .192 \\
\hline
\end{tabular}




\begin{tabular}{llllll}
\hline Defendant Responsibility X Defendant Rel. (MuslimB) & -.03 & .37 & -.09 & .933
\end{tabular}

Note. Non-disclosed Defendant religion was used as a reference category for Defendant Rel. (MuslimB) and Defendant Rel (Chrstian). Christian Defendant Religion was used as a reference category for Defendant Rel. (Muslim). Values for low and high moderator levels are -1 standard deviation from the mean for Low, and +1 standard deviation for High.

Table 7 - Summary of model statistics for Hayes PROCESS Model 1, predicting the effects of defendant religion, and effect of moderation by defendant stereotypes on verdict outcome.

\begin{tabular}{llllll}
\hline Predictor & $B$ & $S E$ & $z$ & Sig.
\end{tabular}

\section{Logistic Regression Model}

Defendant Rel. (Muslim)

$\begin{array}{llll}.34 & .31 & 1.10 & .27\end{array}$

Defendant Rel. (Christian)

$\begin{array}{llll}-.11 & .29 & -.40 & .69\end{array}$

Religious CCC

$.23 \quad 1.84 \quad .066$

\section{Moderator Level Low}

Religious CCC X Defendant Rel. (Muslim)

$\begin{array}{llll}.60 & .49 & 1.22 & .221\end{array}$

Religious CCC X Defendant Rel. (Christian)

$\begin{array}{llll}-.51 & .38 & -1.37 & .171\end{array}$

Religious CCC X Defendant Rel. (MuslimB)

$\begin{array}{llll}.09 & .43 & .20 & .842\end{array}$

\section{Moderator Level At Mean}

$\begin{array}{lllll}\text { Religious CCC X Defendant Rel. (Muslim) } & .34 & .31 & 1.10 & .27 \\ \text { Religious CCC X Defendant Rel. (Christian) } & -.11 & .29 & -.40 & .69 \\ \text { Religious CCC X Defendant Rel. (MuslimB) } & .30 & .30 & .76 & .447 \\ \text { Moderator Level High } & & & & \\ \text { Religious CCC X Defendant Rel. (Muslim) } & & & & \\ \text { Religious CCC X Defendant Rel. (Christian) } & .09 & .41 & .21 & .836 \\ \text { Religious CCC X Defendant Rel. (MuslimB) } & .29 & .51 & .56 & .573\end{array}$

Note. Non-disclosed Defendant religion was used as a reference category for Defendant Rel. (MuslimB) and Defendant Rel (Christian). Christian Defendant Religion was used as a reference category for 
Defendant Rel. (Muslim). Values for low and high moderator levels are -1 standard deviation from the mean for Low, and +1 standard deviation for High.

\section{Mediators}

Tables 8 and 9 present the analyses of religion CCC as a potential mediator for defendant religion on verdict outcome. Hayes PROCESS (2012) was used to model the potential relationship. The initial model of defendant religion on religion $\mathrm{CCC}$ was significant $F(2,455)=$ 93.70, $p<.001, R^{2}=.29$, and the effects of the individual dummy coded defendant religion conditions are displayed in Table 8. Muslim defendant religion significantly predicted religion $\mathrm{CCC}$ when the Christian defendant was used as the reference category, $b=1.26, p<.001$, and when Non-disclosed was used as the reference category, $b=.1 .45, p<.001$, indicating that Muslim defendants received higher ratings of religion CCC than either Christian defendants or defendants with no disclosed religion. In the Hayes PROCESS model, the relative direct effect of defendant religion on verdict was not statistically significant when religion CCC was included as a mediator. Finally, the relative indirect effects of defendant religion through religion $\mathrm{CCC}$ had a statistically significant relationship with verdict outcome for Muslim defendant religion $a b=.26$, $95 \%$ CI $[.015, .545]$ with Christian defendant religion as reference, and again $a b=.30,95 \% \mathrm{CI}$ $[.010, .616]$ with non-disclosed religion as reference. To summarize, Muslim defendant religion predicts higher religion CCC scores as compared to Christian defendant religion or defendants with no disclosed religion, and higher religion $\mathrm{CCC}$ in turn predicts more guilty verdicts. This suggests that the effect of defendant religion on verdict outcome may be mediated by religion CCC. As further tests showed, defendant religion did not significantly predict verdict outcome 
with religion $\mathrm{CCC}$ in the model $b=.10,95 \% \mathrm{CI}[-.155, .362]$, indicating that this is a full mediation.

Table 8 - Summary of model statistics for Hayes PROCESS Model 4, predicting the effects of defendant religion on religion $C C C$.

\begin{tabular}{lllll}
\hline Predictor & $\boldsymbol{B}$ & $\boldsymbol{S E}$ & $\boldsymbol{t}$ & Sig. \\
\hline Effect of Defendant Rel. on Religion CCC & & & & \\
Defendant Rel. (Muslim) & 1.26 & .12 & 10.55 & .000 \\
Defendant Rel. (Christian) & .19 & .12 & 1.65 & .100 \\
Defendant Rel. (MuslimB) & 1.45 & .11 & 12.86 & .000
\end{tabular}

Note. Non-disclosed Defendant religion was used as a reference category for Defendant Rel. (MuslimB) and Defendant Rel (Christian). Christian Defendant Religion was used as a reference category for Defendant Rel. (Muslim).

Table 9 - Summary of model statistics for Hayes PROCESS Model 4, Predicting the Relative Direct and Indirect Effects of Defendant Religion on Verdict Outcome.

\begin{tabular}{|c|c|c|c|c|c|c|}
\hline Predictor & $\boldsymbol{B}$ & $S E$ & $Z$ & Sig. & $\begin{array}{l}\text { Lower } \\
\text { CI }\end{array}$ & $\begin{array}{l}\text { Upper } \\
\text { CI }\end{array}$ \\
\hline \multicolumn{7}{|c|}{$\begin{array}{l}\text { Relative Direct Effects of Defendant Rel. } \\
\text { on Verdict }\end{array}$} \\
\hline Defendant Rel. (Muslim) & .39 & 30 & 1.31 & .190 & -.191 & .963 \\
\hline Defendant Rel. (Christian) & -.22 & .27 & -.81 & .418 & .308 & -.742 \\
\hline Defendant Rel. (MuslimB) & .17 & .29 & .59 & .55 & -.389 & .727 \\
\hline \multicolumn{7}{|c|}{ Relative Indirect Effects Defendant } \\
\hline \multicolumn{7}{|l|}{ Religion } \\
\hline Defendant Rel. (Muslim) & $.26^{*}$ & .13 & $\mathrm{~N} / \mathrm{A}$ & $\mathrm{N} / \mathrm{A}$ & .015 & .545 \\
\hline Defendant Rel. (Christian) & .04 & .03 & N/A & $\mathrm{N} / \mathrm{A}$ & .132 & -.001 \\
\hline
\end{tabular}




\begin{tabular}{lllllll}
\hline Defendant Rel. (MuslimB) & .30 & .15 & N/A & N/A & .010 & .616
\end{tabular}

Note. Non-disclosed Defendant religion was used as a reference category for Defendant Rel. (MuslimB) and Defendant Rel (Chrstian). Christian Defendant Religion was used as a reference category for Defendant Rel. (Muslim).

Lastly, religion CCC was examined for potential moderation effects. A summary of the results can be seen in Tables 10 and 11. An additional Hayes PROCESS model was conducted with defendant stability and defendant responsibility to examine if they moderate the predictive effect of religion CCC on verdict outcome. In the first model, defendant stability was found to significantly predict verdict outcome, but its overall interaction with religion CCC was not significant. However, the effect of religion CCC on verdict outcome was moderated by low defendant stability, $b=.42, p=.033$. This indicates that higher scores in religion CCC predicted more guilty verdicts, but only when participants viewed the defendant as less likely to commit future crimes. In the second model, defendant responsibility was found to significantly predict verdict outcome, but its overall interaction with religion CCC was not statistically significant. Additionally, the effect of religion $\mathrm{CCC}$ on verdict outcome was moderated by mean defendant responsibility, $b=.27, p=.011$. Similarly, this shows that higher scores in religion CCC were related to more guilty verdicts when the defendant's responsibility was perceived as middling, but not when the defendant was viewed as either being very responsible for their actions or largely not responsible. Finally, the effect of religion CCC verdict outcome was moderated by high defendant responsibility, $b=.25, p=.043$. Accordingly, this shows the effect of religion CCC was present when participants viewed the defendant as highly responsible for his actions, but not at average or low assessments of defendant responsibility. 
Table 10 - Summary of model statistics for Hayes PROCESS Model 1, predicting the effects of religion CCC, and effect of moderation by defendant stability, on verdict outcome.

\begin{tabular}{|c|c|c|c|c|}
\hline Predictor & $\boldsymbol{B}$ & $S E$ & $z$ & Sig. \\
\hline \multicolumn{5}{|l|}{ Logistic Regression Model } \\
\hline Defendant Stability & $1.26^{* * *}$ & .155 & 8.15 & .000 \\
\hline Religious CCC & .18 & .11 & 1.64 & .101 \\
\hline Defendant Stability X Religious CCC & $-.203^{*}$ & .12 & -2.02 & .044 \\
\hline \multicolumn{5}{|l|}{ Varying Moderator Levels } \\
\hline Low Defendant Stability X Religious CCC & $.42^{*}$ & .20 & 2.13 & .033 \\
\hline Mean Defendant Stability X Religious CCC & .18 & .11 & 1.64 & .101 \\
\hline High Defendant Stability X Religious CCC & -.07 & .12 & -.56 & .577 \\
\hline
\end{tabular}

Note. Values for low and high moderator levels are -1 standard deviation from the mean for Low, and +1 standard deviation for High.

Table 11 - Summary of model statistics for Hayes PROCESS Model 1, predicting the effects of religion $C C C$, and effect of moderation by defendant responsibility, on verdict outcome.

\begin{tabular}{|c|c|c|c|c|}
\hline Predictor & $B$ & $S E$ & $z$ & Sig. \\
\hline \multicolumn{5}{|l|}{ Logistic Regression Model } \\
\hline Defendant Responsibility & .77 & .09 & 8.59 & .000 \\
\hline Religious CCC & .27 & .11 & 2.56 & .011 \\
\hline Defendant Responsibility X Religious CCC & -.01 & .07 & -.15 & .880 \\
\hline \multicolumn{5}{|l|}{ Varying Moderator Levels } \\
\hline Low Defendant Responsibility X Religious CCC & .29 & .17 & 1.66 & .098 \\
\hline Mean Defendant Responsibility X Religious CCC & $.27^{*}$ & .11 & 2.56 & .011 \\
\hline High Defendant Responsibility X Religious CCC & .25 & .13 & 2.03 & .053 \\
\hline
\end{tabular}


Note. Values for low and high moderator levels are -1 standard deviation from the mean for Low, and +1 standard deviation for High.

\section{Stereotypes \& Attributions}

The hypotheses for defendant race (1), defendant religion (2), and defendant race/defendant religion interaction (3) all included sub-hypotheses about their expected effects on stereotypes and attributions. To investigate these sub-hypotheses, five 3x3 ANOVA tests were conducted, wherein the independent variables were defendant race and defendant religion. The dependent variables were as follows: (1) religion cultural criminality checklist, (2) race cultural criminality checklist, (3) defendant responsibility, (4) defendant stability, and (5) defendant internality.

Religion Cultural Criminality Checklist. Sub-hypothesis 2A predicted that Muslim Canadians would receive higher participant ratings of religion CCC than Christian Canadians. Similar to the above analyses, I observed a main effect of defendant religion, such that participants held differing stereotypes of Canadians with no disclosed religion $(M=3.09, S D=$ $.08)$, Christian Canadians $(M=3.29, S D=.10)$, and Muslim Canadians $(M=4.53, S D=.09)$, $F(2,455)=84.74, p<.001$, supporting hypothesis $2(\mathrm{~A})$. Furthermore, a post-hoc comparisons test using the Tukey HSD showed that ratings of Muslim Canadians differed significantly at $p<$ .001 from those of Christian Canadians, and at $p<.001$ from those of Canadians with no disclosed religion, but that Christian Canadians and Canadians with no disclosed religion did not receive significantly different ratings.

Race Cultural Criminality Checklist. Sub-hypothesis 1A suggested that Black and Arab Canadians would receive higher participant ratings of race CCC than White Canadians. 
Firstly, the results showed a main effect of defendant race on Race Cultural Criminality Checklists, in that participants held differing stereotypes of White Canadians $(M=3.56, S D=$ $.08)$, Black Canadians $(M=4.39, S D=.07)$, and Arab Canadians $(M=4.65, S D=.09), F(2,455)$ $=45.73, p<.001$, supporting hypothesis 1 (A). Additionally, a post-hoc comparison test using the Tukey HSD showed that ratings of White Canadians significantly differed at $p<.001$ from those of Black Canadians, and at $p<.001$ from those of Arab Canadians, but that Black and Arab Canadians did not show significantly different ratings.

Defendant Responsibility. Hypothesis 1B predicted that Black and Arab defendants would receive higher participant ratings of defendant responsibility than White defendants, hypothesis $2 \mathrm{~B}$ predicted that Muslim defendants would receive higher participant ratings of defendant responsibility than Non-disclosed or Christian defendants, and hypothesis 3C suggested the defendant religion/defendant race interaction would show higher participant ratings of defendant responsibility for Muslim/Arab defendants than other combinations. To begin, results did not show a main effect of defendant race on defendant responsibility, as results indicated that participant ratings of defendant responsibility did not differ significantly among White defendants $(M=5.15, S D=.13)$, Black defendants $(M=5.20, S D=.12)$, and Arab defendants $(M=5.23, S D=.16), F(2,455)=.22, p=.805$, failing to support hypothesis $1(\mathrm{~B})$. Additionally, I did not find a main effect of defendant religion on defendant responsibility; results showed that participant ratings of defendant responsibility did not differ between defendants with no disclosed religion $(M=5.15, S D=.12)$, Christian defendants $(M=5.17, S D$ $=.16)$, and Muslim defendants $(M=5.32, S D=.13), F(2,455)=.50, p=.610$, failing to support hypothesis 2(B). Lastly, I found no significant effect of the defendant race/defendant religion interaction on defendant responsibility, as results showed participant views of defendant 
responsibility did not significantly differ among combinations of defendant religion and defendant race, $F(4,455)=.55, p=.697$, failing to support hypothesis $3(\mathrm{~A})$.

Defendant Stability. Hypothesis 1C predicted that Black and Arab defendants would receive higher participant ratings of defendant stability than White defendants, hypothesis $2 B$ predicted that Muslim defendants would receive higher participant ratings of defendant stability than Non-disclosed defendants or Christian defendants, and hypothesis $3 \mathrm{C}$ suggested the defendant religion/defendant race interaction would show higher participant ratings of defendant stability for Muslim/Arab defendants than for other combinations. Firstly, I did not observe main effect for of defendant race on defendant stability, as results indicated that participants did not differ in their ratings of defendant stability among White defendants $(M=4.88, S D=.09)$, Black defendants $(M=4.90, S D=.08)$, and Arab defendants $(M=4.94, S D=.10, F(2,455)=.10, p=$ .907 , providing no support for hypothesis $1(\mathrm{C})$. Secondly, I observed a main effect of defendant religion on participants' ratings of defendant stability, in that ratings were significantly different between defendants with no disclosed religion $(M=4.82, S D=.10)$, Christian defendants $(M=$ 4.82, $S D=.10)$, and Muslim defendants $(M=5.13, S D=.09), F(2,455)=4.92, p=.008$, which provided support for hypothesis 2(C). A post-hoc comparison test using the Tukey HSD showed that ratings of Muslim defendants differed significantly at $p<.028$ from those of Christian defendants, and at $p<.003$ from those defendants with no disclosed religion, but that Christian defendants and defendants with no disclosed religion did not receive ratings that significantly differed. Lastly, I found no significant effect of the defendant race/defendant religion interaction on participants' ratings of defendant stability, as results indicated that participant ratings did not statistically differ in how they perceived defendant stability among the combinations of 
defendant race and defendant religion $F(4,455)=.55, p=.700$, providing no support for hypothesis $3(\mathrm{~B})$.

Defendant Internality. Hypothesis 1D predicted that Black and Arab defendants would receive higher participant ratings of defendant internality than White defendants, hypothesis $2 \mathrm{~B}$ predicted that Muslim defendants would receive higher participant ratings of defendant internality than Non-disclosed or Christian defendants, and hypothesis 3C suggested the defendant religion/defendant race interaction would show higher participant ratings of defendant internality for Muslim/Arab defendants than for other combinations. Firstly, results showed a main effect for defendant race on participants' ratings of defendant internality, where participants statistically differed in the ratings of defendant internality between White defendants $(M=3.95, S D=.16)$, Black defendants $(M=4.52, S D=.14)$, and Arab defendants $(M=4.12$, $S D=.19), F(2,455)=3.97, p=.019$, supporting hypothesis $1(\mathrm{D})$. Additionally, a post-hoc comparison test using the Tukey HSD showed that ratings for White defendants were significantly lower at $p<.015$ from those of Black defendants, but Black defendants and Arab defendants did not receive significantly different ratings, nor did White defendants and Arab defendants. Finally, results showed no main effect of defendant religion on participants' ratings of defendant internality, such that participants did not statistically differ in the ratings of defendant internality between defendants with no disclosed religion $(M=4.15, S D=.14)$, Christian defendants $(M=4.23, S D=.18)$, and Muslim defendants $(M=4.21, S D=.16)$, $F(2,455)=.07, p=.93$, failing to produce support for sub-hypotheses 2(D). Lastly, I observed no significant effect of the defendant race/defendant religion interaction on participants' ratings of defendant internality, as results indicated participants did not statistically differ in the internality 
that was attributed for the defendant's behaviour among combinations of defendant religion and defendant race, $F(4,455)=.59, p=.673$, providing no support for hypothesis $3(\mathrm{C})$.

Table 12 - Summary of participant ratings (race CCC, religion CCC, defendant stability, defendant responsibility, defendant internality) across conditions

\begin{tabular}{lllllllllllll}
\hline $\begin{array}{l}\text { Def. } \\
\text { Race }\end{array}$ & $\begin{array}{l}\text { Def. } \\
\text { Religion }\end{array}$ & \multicolumn{2}{c}{$\begin{array}{c}\text { Racial } \\
\text { Stereotypes }\end{array}$} & $\begin{array}{c}\text { Religion } \\
\text { CCC }\end{array}$ & $\begin{array}{c}\text { Def. } \\
\text { Stability }\end{array}$ & & Def. Resp. & \multicolumn{2}{c}{$\begin{array}{c}\text { Def. } \\
\text { Attribution }\end{array}$} \\
& & Mean & SD & Mean & SD & Mean & SD & Mean & SD & Mean & SD \\
White & Christian & 3.60 & .12 & 3.28 & .13 & 4.87 & .13 & 5.20 & .20 & 4.09 & .20 \\
Black & Christian & 4.68 & .13 & 3.27 & .13 & 4.84 & .14 & 5.15 & .21 & 4.66 & .21 \\
Arab & Christian & 4.84 & .23 & 3.32 & .24 & 4.74 & .24 & 5.17 & .37 & 3.94 & .37 \\
White & Muslim & 3.50 & .17 & 4.45 & .18 & 4.96 & .18 & 5.04 & .28 & 3.98 & .28 \\
Black & Muslim & 4.23 & .12 & 4.41 & .13 & 5.19 & .13 & 5.46 & .20 & 4.32 & .20 \\
Arab & $\begin{array}{l}\text { Muslim } \\
\text { Nhite }\end{array}$ & 4.65 & .13 & 4.72 & .14 & 5.23 & .14 & 5.46 & .21 & 4.33 & .21 \\
disclosed & 3.58 & .13 & 3.10 & .13 & 4.81 & .14 & 5.22 & .21 & 3.77 & .21 \\
Black & $\begin{array}{l}\text { Non- } \\
\text { disclosed }\end{array}$ & 4.25 & .13 & 3.11 & .13 & 4.67 & .14 & 4.98 & .21 & 4.56 & .21 \\
Arab & $\begin{array}{l}\text { Non- } \\
\text { disclosed }\end{array}$ & 4.48 & .13 & 3.10 & .13 & 4.82 & .14 & 5.24 & .21 & 4.10 & .21 \\
\hline
\end{tabular}




\section{Discussion}

Past research has shown how ambiguity in task instructions opens the door for stereotypes or other biases to creep into decision making (Pfeifer \& Bernstein, 2003). Legal scholars noted similar concerns with S. 83.221, taking issue with the ill or undefined terms and vague wording of the offence, suggesting it may be unfairly applied to Muslim or Arab Canadians (Abell, 2015; Canadian Bar Association, 2015; Morgan, 2011). Stereotype research within Canada on Arab Canadians is sparse, but a study in the United States examining perceived cultural stereotypes found some of the most common responses for Arabs were Terrorists, Oppress Women, and Dangerous (Ghavami, 2013). These responses may indicate the direction biases could take jurors if information was thin or instructions unclear. The goal of this study was to investigate the relationship between defendant race, defendant religion, and S. 83.221, Promoting or Advocating for the Commission of Terrorism Offences. Specifically, I hoped to see if defendants of a particular race, ideology, or a combination of the two would receive more guilty verdicts than others, and if this change in verdicts would be driven by the publicly held stereotypes of those groups.

\section{Attributions}

In the jury context, attribution theory suggests that participants who believe the criminal behavior of a defendant is best explained by internal attributes such as personal choices or morality are inclined towards more punitive responses and recommend heavier sentences that support deterrence. In contrast, participants who believe that the criminal behavior is best explained by external attributes, such as necessity or extenuating social pressures, prefer rehabilitative sentencing, and are less conviction prone (Templeton \& Hartnagel, 2012; Unnever, Cochran, Cullen, \& Applegate 2008; Unnever, Cullen, \& Jones 2010). Following past research, 
in this study I found that when participants rated the defendant as more likely to recommit similar offences or the same offense, they were more likely to find the defendant guilty. Likewise, participant belief that the defendant understood and intended the outcome of his actions, and was more personally responsible, predicted more guilty verdicts. Curiously, contrary to past research on the impact of attributions on jury decision making, no effect was found for the subscale of defendant internality. Defendant internality was measured with three items pertaining to whether the crime was committed more due to the defendant's characteristics or societal reasons. Previously, Jones and Kaplan (2003) found stronger defendant internality attributed to defendants when their race matched stereotypes of the crime, and Templeton and Hartnagel (2012) found harsher sentences when using a similar measure for internal attributions. I hypothesized a similar link between defendant internality and verdicts. The lack of an effect found may have been due to some participant confusion. The items on defendant internality directly addressed the degree to which the defendant's actions could be attributed to internal motivations as opposed to external motivations, and there is the possibility that these questions were not conveyed as clearly as the other subscales, as the questions were perhaps framed in a fashion too abstract for participants. The other two attribution subscales may have had the benefit of providing more specific examples as compared to Defendant Internality, and thus were easier to understand. Lastly, it is possible Defendant Internality was not as relevant to jurors as Defendant Stability and Defendant Responsibility in determining guilt for anti-terrorism cases.

\section{Cultural Stereotypes}

Following the hypothesis, participants believed that the Canadian public viewed Muslim Canadians as possessing more criminal stereotypes than either Christian Canadians or Canadians with no disclosed religion. Furthermore, participants provided higher ratings of cultural 
criminality stereotypes for Black and Arab Canadians than their White Canadian counterparts. These results are similar to those found in the work of Ghavami (2013), who examined cultural stereotypes with free responses pertaining to race, and found predominantly negative terms associated with Arab Americans. However, Ghavami (2013) was concerned that participants were not appropriately distinguishing Arabs as a racial group from Muslims as a religious group, and applying negative stereotypes from either group. Interestingly, this study found both Muslim Canadians and Arab Canadians were more criminally stereotyped compared to their counterparts, and this is possibly due to a poor understanding of the distinction in our sample as well. Lastly, this might indicate that Canadians are similar to Americans, and hold negative views of Arab or Muslim Canadians, possibly linking them to terrorism.

Although some differences were seen in participant ratings of stereotypes between races, racial cultural stereotypes did not predict verdict outcome. Previous research (Ewanation \& Maeder, accepted) has discussed a possible explanation; it may be that mock jurors who rate racial groups as being more stereotyped by the Canadian public might be less susceptible to those stereotypes than mock jurors that believe those stereotypes are largely no longer present in society. Additionally, participants who believed the Canadian public held more cultural criminality stereotypes of the defendant's religion were more likely to find the defendant guilty, but only under certain conditions. Specifically, participants were more likely to find the defendant guilty when they rated the defendant as more likely to commit the same offence or similar offenses in the future, or attributed the cause of the defendant committing the crime more to personal than societal reasons. Broadly, this could link back to attribution theory, which describes how jurors who found the defendant more personally responsible or likely to commit future crimes would be more prone to conviction and recommending harsher sentences 
(Unnever, Cochran, Cullen, \& Applegate 2010; Unnever, Cullen, \& Jones 2008). When participants assessed the defendant as such, stereotypes could then play an influential role. Furthermore, these results are similar to those of Gordon et al. (1988), who found defendants received more internal attributions when a crime matched stereotypes of the defendant's race than when it did not. As seen in Ghavami (2013), stereotypes associated with Arabs in America include terms such as 'Terrorist'. My findings support that Arab Canadians are perceived as more criminally stereotyped than White or Black Canadians, and that these stereotypes lead to more convictions for terrorism charges when the jurors also rate the defendant as likely to commit further offenses. This may suggest that there may be a stereotyped link between Arab race and terrorism offences, but further research will be needed to establish it.

\section{Defendant Race}

Defendant race has been an oft researched topic in jury decision-making, and past research has produced some conflicting results. Although recent meta-analyses have found a small effect of out-group race, with mock jurors finding defendants guilty more often if they are of a different race (Devine, \& Caughlin, 2014; Mitchell, Haw, Pfeifer, \& Meissner, 2005), other studies have found contradictory effects (Marcus-Newhall, Blake, \& Baumann, 2002; Mazzella \& Feingold, 1994). In this study, I hypothesized that White defendants would receive fewer guilty verdicts than Black or Arab Canadians. This hypothesis was based on the fact the Canadian population is predominantly White, and my sample would reflect this. Similarity-leniency theory would suggest the White participants would view the White defendants more favourably than Black or Arab defendants. However, this study found no effect of defendant race on mock jurors' verdict outcomes, contrary to my expectations. Recent studies with Canadian samples have found conflicting results for race effects. Some such as Maeder et al. (2015) found mock jurors 
produced harsher sentence recommendations for Aboriginal defendants than White defendants, but this is not always the case, as seen in Ewanation and Maeder (accepted), which did not find a statistically significant effect of defendant race on verdict, and found Aboriginal eyewitnesses to be rated more as accurate than their White counterparts. As noted above, participants did identify Black and Arab Canadians as being more stereotyped by the Canadian public. However, this did not result in more guilty verdicts for Black and Arab Canadians than for White Canadians, contrary to what I would have expected considering the aversive racism framework. The aversive racism framework suggests that individuals are more influenced by biases in situations where the social norms are vague and the instructions are ambiguous or absent. S. 83.221 has been noted by legal scholars to be ambiguous, using terminology lacking legal definitions (Abell, 2015; Canadian Bar Association, 2015; Morgan, 2011). This would suggest an increase in guilty verdicts for Black or Arab Defendants, as the lack of clear instructions would lead jurors to rely more on stereotypes of the defendant's race or ideology, and both Black and Arab Canadians were found more criminally stereotyped than their White counterparts. However, as the participants showed awareness of the biases in Canadian society, they may have attempted to correct for these in their decision-making, possibly reducing or eliminating the effect these stereotypes would have on their decision making. Furthermore, it is possible the juror instructions provided or the arguments presented in the transcript served to reduce ambiguity, and corresponding opportunity for bias to influence juror decisions. Additionally, it is possible that in the context of an anti-terrorism case, stereotypes relating to religious ideology trump racial stereotypes in juror decision-making. Jurors still possess racial stereotypes, but may find religious stereotypes more relevant to terrorism, and rely on them more when other information is sparse. Lastly, this could also provide some cautious optimism for the legislation, as this may 
indicate S. 83.221 is not as ambiguous as legal scholars feared. However, future research will be necessary to confirm these results.

Lastly, differences among races were found for some attribution measures. White defendants received more internal attribution ratings than either Black or Arab defendants. Given the predominantly White Canadian participant demographics, I hypothesized an out-group effect wherein White Canadians would have received less internal attribution ratings than their Black and Arab counterparts. However, similar to the concerns above, if Canadians were aware of the stereotypes Arab and Black Canadians must contend with, they may have taken those into account when assigning attribution scores, and attempted to correct for bias. Furthermore, jurors may have considered the prevalence of those stereotypes an example of societal responsibility for the crime. For instance, mock jurors may have believed that those stereotypes are conducive or responsible for societal issues such as systemic racism, and may have viewed them as a driving force behind any radicalization of the defendant. In this regard, stereotypes held by the public of a race or ideology could then be an instance of society's responsibility for the crime that occurred, or in part explain the defendant's presence in the justice system.

\section{Defendant Religion}

As with defendant race above, similarity-leniency theory holds that mock jurors may treat defendants of similar religious leanings with more leniency than those that differ from them. Investigating this, Kerr, Hymes, Anderson, and Weathers (1995) found religious similarity to be positively related to the evaluation of defendants in a trial with weak evidence. Likewise, in this study I predicted that the ambiguity present in S. 83.221 would function similarly to weak evidence, and lead to more guilty verdicts for Muslim defendants as the participant sample was predominantly Christian or non-religious. A significant effect was found for defendant religion, 
in which Muslim defendants received more guilty verdicts than their Christian and non-religious counterparts, albeit only when other variables were not included in the model. However, results also showed that participant ratings of how criminally stereotyped the defendant's religion was fully mediated the effect of defendant religion. This means the effect of defendant religion can be explained by the degree to which participants found the defendant's religious group to be criminally stereotyped. Essentially, participants found the defendant guilty more often when they were Muslim, as compared to their Christian and non-disclosed counterparts, but predominantly so when they believed the defendant's religious group to be quite criminally stereotyped by the Canadian public. This is broadly appropriate with the ideas raised in race-crime congruency theory, albeit for the defendant's religious stereotypes rather than racial stereotypes.

Interestingly, defendant religion also influenced verdict outcome when participant appraisals of defendant responsibility were middling, and a weak effect was shown for when participant ratings of defendant responsibility were low. This indicates when the personal blame of the defendant was assessed as high, participant determination of guilt was relatively clear. However, when participants were not as certain of the defendant's personal fault for the crime, the defendant's religious ideology began to play a relevant role. Furthermore, this effect was only found for defendants with a Muslim background, as compared to defendants with no disclosed religion. Participants in this study may have provided more guilty verdicts for Muslim defendants because they find Muslim defendants to more stereotypically fit the crimes in question, and therefore require less information to convict, similar to race-crime congruency. However, this study did not systematically investigate the effect of race- or religious-crime congruency - this merely points out one crime-stereotype combination, so the conclusions I can make are limited. Furthermore, the results follow the Director's Cut theory of juror decision- 
making, in that a Muslim defendant accused of terrorism offenses may follow the more prototypical idea of what a terrorist offender is, as compared to defendants of other ideologies. Lastly, the relative weakness of this effect could be explained along the lines discussed for defendant race; participants may have been aware of societal stereotypes for religious groups, and attempted to self-correct for them in their evaluation of the defendant.

\section{Defendant Race/Religion Relationship}

The goal of this study was to examine if the ambiguity noted by some legal scholars in the new terrorism offense (Abell, 2015; Canadian Bar Association, 2015; Morgan, 2011) would present a situation where the biases of defendant race and religion would lead to different verdicts for different racial and religious groups. In particular, the combination of Muslim and Arab was predicted to receive more guilty verdicts than other combinations, following the Director's Cut model of juror decision-making (Devine, 2012). However, no effect was found for the combination of defendant race and religion on verdict outcome or any of the attribution measures. It is possible the lack of effect for the Muslim/Arab combination could be due to the lack of significant effects found for defendant race across the board. Furthermore, Canadians might be aware of their need to correct for perceived racism, but fail to take the same steps for religious stereotypes. Lastly, the Canadian stereotypes of offenders that commit terrorism offenses might simply be tied more to ideology than to race.

\section{Limitations}

This study was conducted following many of the contemporary practices of jury decisionmaking research in Canada, but the nature of the research and resources available entailed a series of limitations with the current design. Firstly, the participants in my study were not actual jurors, but rather mock jurors composed of an online sample from the Canadian population, and 
screened for the basic qualifiers required to be a prospective juror in Canada. However, as jurors are prohibited from disclosing their experiences in the jury setting (Canada Criminal Code, 1985, s. 649), the use of mock jurors is necessary for Canadian research. Furthermore, the selection process used by the courts may have nuances to it not reflected by this study's screening questions. However, while nuances in juror selection may be a relevant factor in juror decision making and a good avenue for future research, it is beyond the scope of this study.

The current study made use of an online sample recruited via Qualtrics panels. This limited the control I had over the environment in which the participants viewed the material; participants may have retained critical trial information less if they responded to the survey in a distracting environment, or retained it better if they made use of assets like note-taking. However, the use of an online sample improved some ecological validity, as it allowed recruitment from a broader range of demographics than simply students. Wiener, Krauss, and Lieberman (2011) noted in their review that undergraduate mock jurors might not engage with trial transcripts the same way community samples do, suggesting the two groups might process difficult written materials differently. Similarly, Bornstein, Golding, Neuschatz, Kimbrough, Reed, Magyarics, and Luecht, (2017) examined differences in sample selection and jury stimulation, and found written testimony and video testimony moderated differences between students' and non-students' verdict decisions. They suggested these differences may be due to how the respective groups engage with complex written materials. Due to this, I opted for a more ecologically valid route with community members, despite the impact it would have on my control over participant conditions. Secondly, the manner in which the trial information was provided to mock jurors raised some ecological validity concerns. There may be differences in the content of this study's mock trial transcripts and the information that would be provided to 
jurors during real trials concerning S. 83.221. The trial information was presented as trial transcripts that participants read. This differs from actual jurors who receive testimony directly from witnesses in the courtroom. However, past research (Bornstein, 1999) has examined some common areas of low ecological validity in jury research, and found few differences between transcript studies and more realistic attempts at simulating the juror experience. Moreover, though Bornstein et al. (2017) found differences between written testimony and video testimony, the direction of the effect was inconsistent. Students found defendants guilty more often than nonstudents, but the reverse was true for sentence recommendations, with nonstudents opting for harsher outcomes. Additionally, Pezdek, Avila-Mora and Sperry (2010) looked specifically at juror perceptions of eyewitness testimony between trial transcripts and video, and in two studies found no significant interactions based on the stimuli provided to the jury. Furthermore, the written transcripts may serve to remove extra-legal factors such as the appearance and demeanor of those providing testimony, and their absence helps in reducing potential confounds. These factors would be relevant in an actual courtroom, and their removal does reduce the ecological validity of the study, but it provides the potential for improved internal validity and a greatly reduced cost in resources. Wiener et al. (2011) suggested following a two-step process. First, studies would be designed with strong internal validity in mind. Follow up research could then be conducted with an eye towards incorporating more realistic trial processes. My selection of trial stimulation and participants intended to provide a good balance between resources used and internal/ecological validity. Building upon my findings with even greater ecological validity presents a good avenue for future research.

Furthermore, this study involved participants reading trial information and making a verdict decision on their own, with no deliberation process included. How deliberation affects 
the decision-making of jurors and their final verdict is an important area of research, but past research has found the majority of individual juror verdicts prior to deliberation mirrors the final outcome a substantial percentage of the time (Devine, Buddenbaum, Houp, Stolle, \& Studebaker, 2007; Devine, Olafson, Jarvis, Bott, Clayton, \& Wolfe, 2006), which demonstrates the value of understanding juror decision-making on the individual level.

Finally, a percentage of the participant pool (approximately $30 \%$ ) were dropped due to failing to pass manipulation or attention checks. These checks were included to ensure data included in analyses came from participants that understood the facts of the trial, accurately perceived the manipulations, and paid attention throughout the study. This screening improved the quality of the responses and the conclusions I can draw from the data. Section 83.221 is a relatively new addition to the criminal code, and the checks ensured participants did not mistake the law in question when responding. Additionally, the failure rate was not notably different from studies examining online crowdsourcing (Berinsky, Margolis, \& Sances, 2014; Peer, Vosgerau, \& Acquisti, 2013).

Many of these limitations can be attributed to the restrictions in scope and budget of this project. Research into Canada's terrorism laws remains scarce, and some limitations, such as the absence of deliberation, present avenues for future research.

\section{Implications}

Participant ratings for the cultural criminality checklists found stereotypes held by the Canadian public that may prove a concern for the Canadian courts. Muslim Canadians were viewed as more criminally stereotyped than either Christian Canadians or Canadians with no disclosed religion, and participants believed Black and Arab Canadians to be more criminally 
stereotyped than White Canadians. While these differences did not lead to statistically significant differences regarding verdicts, past research has suggested that cultural stereotypes might influence behavior, and so these stereotypes could prove to be a concern in other areas (Krueger, 1996). More steps are required to mitigate the criminal portrayal of all these groups in media, discussions, or other public avenues, in the hope of lessening these stereotypes in the future. Additionally, the results provide some room for cautious hope in regard to racial bias in the courts. No effect of defendant race was observed, despite differences in perceived cultural stereotypes, and this may indicate that Canadians are improving at correcting against biases in a courtroom setting. However, this conclusion is limited, and substantial further replication and a broader scope of races and offenses must be investigated before racial effects in the Canadian courtroom will be properly understood.

Lastly, the results concerning the influence of attributive style, specifically perceptions of responsibility and stability, could be of importance to the courts or legislators. The results showed participants provided more guilty verdicts to if they perceived the defendant as more likely to commit another (or the same) offense, and if they held the defendant as more personally responsible for the crime. This may help lawyers better understand what facets of S.83.221 prospective jurors find most incriminating in defendants, and allow them to build their case appropriately. Furthermore, some weak effects were found for defendant religion and stereotypes on verdict outcome. Previous literature has shown low information environments, such as jurors deciding on ambiguously worded laws, may foster such effects (Gaertner, \& Dovidio, 1986). Particularly concerning was the effect found for defendant religion when participants rated the defendant's personal responsibility as middling or low. As legal scholars have noted specifically the broadness of this law (Canadian Bar Association, 2015; Forcese \& Roach, 2015), there 
remains a pressing concern that the S.83.221 may be applied in scenarios where defendant responsibility is uncertain, and lend itself to bias in juror decision-making. Legislators may seek to clarify the wording of this law, removing ambiguity of what constitutes terrorism offences in general, and thereby reduce the potential for extra-legal factors to influence juror decisions concerning it.

\section{Future Directions}

As noted above, this study was conducted using individual responses, and thus failed to include any component addressing deliberation. Examining deliberation might yield interesting insights into how jurors communicate when presented with an unclear law. Sommers (2006) found that racially diverse juries talked longer, considered more case facts, and made fewer errors than racially homogenous juries when considering verdicts for a defendant of a racial outgroup from the jury majority. Likewise, diversity in ideology of jurors might affect how evidence is appraised when jurors consider S.83.221. Additionally, deliberation is simply a necessary part of juror decisions in the Canadian courts, and its inclusion is important to raise the ecological validity of the results.

Furthermore, the scope of S.83.221 is exceptionally broad; as the RCMP has previously noted in internal documents, environmental activists potentially fall under its purview. The specific cause the defendant championed was kept deliberately vague in this study, but different types of ideology - religious, political, or otherwise, may be treated differently by jurors. Additionally, despite significant overrepresentation in the Canadian justice system, Indigenous Peoples of Canada were not examined in this study. Indigenous peoples have been found to be negatively stereotyped in the past (Ewanation \& Maeder, accepted; Harding, 2006; Jiwani, 2009; 
Pfeifer \& Ogloff, 2003), and research will be needed to examine the potential for bias against this group if this law is brought against them.

\section{Conclusion}

The results of the current study were not entirely consistent with the hypotheses, but the findings have highlighted potential areas for concern in the anti-terrorism law examined. Results demonstrated that two attribution measures, defendant stability and defendant responsibility, had a relationship with verdict outcome. Following my hypotheses, defendant religion influenced verdict outcome, but only at some levels of defendant responsibility. Furthermore, although defendant religion only showed a weak effect on verdict outcome, the results indicated it could be explained by stereotypes of the defendant's religious group. Additionally, at some levels, perceptions of defendant stability and defendant responsibility were related to the strength of the effect produced by stereotypes of the defendant's religious group. Although White Canadians received lower criminality stereotype ratings than Black or Arab Canadians, White defendants also received more internal attribution ratings than either Black or Arab defendants. Muslim Canadians received higher stereotype ratings than Christian Canadians and Canadians with no disclosed religion, and Muslim defendants were perceived as more likely to recommit similar offences or the same offense than Christian defendants or defendants with no disclosed religion. Terrorism has remained an important and heavily reported on topic in the media, and it reasonable to expect the Canadian government to legislate a response to these incidents. However, further research will be necessary before Canadian anti-terrorism legislation is free of the considerable criticism it has received for its potential to be biased or misused. 


\section{References}

Abell et al. (2015) Open letter to Parliament: Amend C-51 or kill it. National Post. Retrieved at: http://news.nationalpost.com/full-comment/open-letter-to-parliament-amend-c-51-or-kill-it

Aberson, C. L., Shoemaker, C., \& Tomolillo, C. (2004). Implicit bias and contact: The role of interethnic friendships. The Journal of Social Psychology, 144(3), 335-347. doi:10.3200/SOCP.144.3.335-347

Allison, M., Sweeney, L., \& Jung, S. (2013). A comparison of Canadian and American offender stereotypes. North American Journal of Psychology, 15(3), 589.

Anti-Terrorism Act, Revised Statues of Canada (2015, c. C-51). Retrieved from the Department of Justice Canada website:

http://www.parl.gc.ca/HousePublications/Publication.aspx?Language=E\&Mode=1\&DocId=8 $\underline{056977 \& \text { File }=4}$

Bahdi, R., (2003). No Exit: Racial Profiling and Canada's War Against Terrorism. Osgood Hall Law Journal, 41, 2-3.

Bastanfard, A., Abbasian Nik, M., \& Dehshibi, M.M., (2007) "Iranian Face Database with Age, Pose and Expression," IEEE Int. Conf. on Machine Vision, pp. 50-55.

Berinsky, A. J., Margolis, M. F., \& Sances, M. W. (2014). Separating the shirkers from the workers? making sure respondents pay attention on self-administered surveys. American Journal of Political Science, 58(3), 739-753. doi:10.1111/ajps.12081

Bornstein, B. H. (1999). The ecological validity of jury simulations: Is the jury still out? Law and Human Behavior, 23(1), 75-91. doi:10.1023/A:1022326807441 
Bornstein, B. H., Golding, J. M., Neuschatz, J., Kimbrough, C., Reed, K., Magyarics, C., \& Luecht, K. (2017). Mock juror sampling issues in jury simulation research: A meta-analysis. Law and Human Behavior, 41(1), 13-28. doi:10.1037/lhb0000223

Brauer, M., Wasel, W., \& Niedenthal, P. (2000). Implicit and explicit components of prejudice. Review of General Psychology, 4(1), 79-101. doi:10.1037/1089-2680.4.1.79

Bucolo, D. O. and Cohn, E. S. (2010), Playing the race card: Making race salient in defence opening and closing statements. Legal and Criminological Psychology, 15: 293-303.

Burdett, Joel. (2013). The combined effect of defendant race and alleged gang affiliation on mock juror decision-making. Psychiatry, psychology, and law. (20)2. p.188.

Canadian Anti-Terrorism Act (2001, c. C-36). Retrieved from Open Parliament website:

\section{https://openparliament.ca/bills/41-2/C-36/}

Canadian Bar Association, (2015). Bill C-51, Anti-terrorism Act, 2015 Executive Summary. Ottawa, On.

Criminal Code, R.S.C. 1985, c.46, s.649

Canadian Department of Justice (2016). The Role of the Public: Canada's System of Justice. Retrieved from Government of Canada Website: http://www.justice.gc.ca/eng/csjsjc/just/12.html

Canadian Electronic Library, Canadian Association of University Teachers, (2015). What does C-51 mean for academic and campus free speech? CAUT analysis of Bill C-51. Ottawa, On. Chambers, L., Roth, J., (2014). Prejudice Unveiled: The Niqab in Court. Canadian Journal of Law and Society. 29, pp 381-395. 
Cohn, E. S., Bucolo, D., Pride, M. and Sommers, S. R. (2009), Reducing White Juror Bias: The Role of Race Salience and Racial Attitudes. Journal of Applied Social Psychology, 39: 19531973.

Corenblum, B., \& Stephan, W. G. (2001). White fears and Native apprehensions: An integrated threat theory approach to intergroup attitudes. Canadian Journal of Behavioural Science. 33, 251-268.

Dehshibi, MM. \& Bastanfard, A., (2010) "A new algorithm for age recognition from facial images," Signal Process., Vol. 90 (8), pp. 2431-2444.

Devine, D.J., (2012). Jury Decision Making: The State of the Science. New York: New York University Press.

Devine, D. J., Buddenbaum, J., Houp, S., Studebaker, N., \& Stolle, D. P. (2008;2009;). Strength of evidence, extraevidentiary influence, and the liberation hypothesis: Data from the field. Law and Human Behavior, 33(2), 136-148. doi:10.1007/s10979-008-9144-x

Devine, D. J., \& Caughlin, D. E. (2014). Do they matter? A meta-analytic investigation of individual characteristics and guilt judgments. Psychology, Public Policy, and Law, 20, 109134.

Devine, P. G., \& Elliot, A. J. (1995). Are racial stereotypes really fading? The Princeton trilogy revisited. Personality and Social Psychology Bulletin, 21, 1139-1150.

Devine, D. J., Olafson, K. M., Jarvis, L. L., Bott, J. P., Clayton, L. D., \& Wolfe, J. M. T. (2004). Explaining jury verdicts: Is leniency bias for real? Journal of Applied Social Psychology, 34(10), 2069-2098. doi:10.1111/j.1559-1816.2004.tb02691.x 
Dovidio, J.F., Brigham, J.C., Johnson, B.T., \& Gaertner, S.L. (1996). Stereotyping, prejudice, and discrimination: Another look. In C.N. Macrae, C. Stangor, \& M. Hewstone (Eds.), Stereotypes and stereotyping (pp. 276-319). New York: Guilford.

Dovidio, J.F., \& Gaertner, S.L. (2004). Aversive racism. In M.P. Zanna (Ed.), Advances in experimental social psychology (Vol.36, pp. 1-51). San Diego, CA: Academic Press.

Duke, L. M., \& Desforges, D. M. (2007). Mock juror decision-making in sexual abuse cases. Applied Psychology in Criminal Justice, 3(2), 96-116.

Ekman, P., \& O’Sullivan, M. (1991). Who can catch a liar? American Psychologist, 46, 913-920.

Erber, R. , \& Fiske, S. T. (1984). Outcome dependency and attention to inconsistent information. Journal of Personality and Social Psychology, 47, 709-726.

Faul, F., Erdfelder, E., Buchner, A., \& Lang, A. (2009). Statistical power analyses using GPower 3.1: Tests for correlation and regression analyses. Behavior Research Methods, 41(4), 11491160. doi:10.3758/BRM.41.4.1149

Feagin, J.R., \& Feagin, C.B. (1978). Discrimination American style: Institutional racism and sexism. Englewood Cliffs, NJ: Prentice-Hall.

Fiske, S. (1998). Stereotyping, prejudice, and discrimination. In D. Gilbert, S. Fiske, \& G. Lindzey (Eds.), The handbook of social psychology (pp. 357-411). New York, NY

Fiske, S. T., \& Taylor, S. E. (1991). Social cognition (2nd ed.). New York: McGraw-Hill.

Fleming, W. C. (2006). Myths and stereotypes about Native Americans. The Phi Delta Kappan, 88(3), 213-217. doi:10.1177/003172170608800319

Forcese, C., Roach, K., (2015). Backgrounder \#1: The New Advocating or Promoting Terrorism Offence. Available at: www.nationalsecuritylaw.ca 
Gaertner, S.L., \& Dovidio, J.F. (1986). The aversive form of racism. In J.F. Dovidio, \& S.L. Gaertner (Eds.), Prejudice, discrimination, and racism (pp.61-89). Orlando, FL: Academic Press.

Ghavami, Negin. (2013). An Intersectional Analysis of Gender and Ethnic Stereotypes: Testing Three Hypotheses. Psychology of women quarterly. (37)1. p.113 - 127.

Gibbins, R., \& Ponting, J. R. (1977). Contemporary prairie perceptions of Canada's Native peoples. Prairie Forum, 2, 57-81.

Gorchow, Z. (2006). "Veil Costs Her Claim in Court - Judge: Face Key in Deciding Truth.” Detroit Free Press, October 22.

Gordon, R. A. (1990). Attributions for blue-collar and white-collar crime: The effects of subject and defendant race on simulated juror decisions. Journal of Applied Social Psychology, 20(12), 971.

Gordon, R. A., \& Anderson, K. S. (1995). Perceptions of race-stereotypic and race-nonstereotypic crimes: The impact of response-time instructions on attributions and judgments. Basic and Applied Social Psychology, 16(4), 455-470. doi:10.1207/s15324834basp1604_4

Gordon, R. A., Bindrim, T. A., McNicholas, M. L., \& Walden, T. L. (1988). Perceptions of bluecollar and white-collar crime: The effect of defendant race on simulated juror decisions. The Journal of Social Psychology, 128, 191-197.

Haddock, G., Zanna, M. P., \& Esses, V. M. (1994). The (limited) role of trait-laden stereotypes in predicting attitudes toward Native peoples. British Journal of Social Psychology, 33, 83106.

Hanniman, W. (2008). Canadian Muslims, islamophobia and national security. International Journal of Law, Crime and Justice, 36(4), 271-285. 
Harding, R. (2006). Historical representations of aboriginal people in the Canadian news media. Discourse \& Society, 17(2), 205-235. doi:10.1177/0957926506058059

Hastie, R. (1993). Introduction. In R. Hastie (Ed.), Inside the juror: the psychology of juror decision making (pp. 2-41). New York: Cambridge University Press.

Hayes, A. F. (2009). Beyond baron and kenny: Statistical mediation analysis in the new millennium. Communication Monographs, 76(4), 408-420. doi:10.1080/03637750903310360

Hayes, A. F. (2012). PROCESS: A versatile computational tool for observed variable mediation, moderation, and conditional process modeling. Retrieved from http://www.afhayes.com/ public/process2012.pdf

Hayes, A. F., \& Rockwood, N. J. (2017). Regression-based statistical mediation, moderation, and conditional process analysis: Observations, recommendations, and implementation. Behaviour Research and Therapy, 98, 39-57

Heider, F., (1958) The Psychology of Interpersonal Relations. New York: Wiley

Henry, F., Hastings, P., \& Freer, B. (1996). Perceptions of race and crime in Ontario: Empirical evidence from Toronto and the Durham region. Canadian Journal of Criminology, 38, 469476.

Higgins, P. L., Heath, W. P., \& Grannemann, B. D. (2007). How type of excuse defense, mock juror age, and defendant age affect mock jurors' decisions. The Journal of Social Psychology, 147(4), 371-392. doi:10.3200/SOCP.147.4.371-392 
Hodson, G., Hooper, H., Dovidio, J. F., \& Gaertner, S. L. (2005). Aversive racism in Britain: The use of inadmissible evidence in legal decisions. European Journal of Social Psychology, $35(4), 437-448$.

Jiwani, Y. (2009). Race and the media: A retrospective and prospective gaze. Canadian Journal of Communication, 34(4), 735.

Jones, C. S., \& Kaplan, M. F. (2003). The effects of racially stereotypical crimes on juror decision-making and information-processing strategies. Basic and Applied Social Psychology, 25, 1-13.

Kaplan, R. M., \& Saccuzzo, D. P. (1982). Psychological testing: Principles, applications, and issues. Monterey, Calif: Brooks/Cole Pub. Co.

Katz, D., \& Braly, K. (1933). Racial Stereotypes of one hundred College Students. Journal of Abnormal and Social Psychology, 28, 280-290.

Kerr, N.L., Hymes, R.W., Anderson, A.B., \& Weathers, J.E. (1995). Defendant-juror similarity and mock juror judgments. Law and Human Behavior, 19 (6), 545-567.

Kimantas, J., (2015). C-51's Criminalization of Caring. Alternatives Journal; 41, 3; CBCA.

Krueger, J. (1996). Probabilistic national stereotypes. European Journal of Social Psychology, 26(6), 961-980. doi:10.1002/(SICI)1099-0992(199611)26:6<961::AID-EJSP799>3.0.CO;2-F

Leblance, D., Hannay, C., (2015) Privacy, security, and terrorism: Everything you need to know about Bill C-51. The Globe and Mail. Retrieved from http://www.theglobeandmail.com

Lott, B., \& Maluso, D. (1995). The social psychology of interpersonal discrimination. New York: Guilford Press 
Lynch, M., \& Haney, C. (2009). Capital jury deliberation: Effects on death sentencing, comprehension, and discrimination. Law and Human Behavior, 33(6), 481-496.

Morgan E., (2011). Surveillance and Privacy in the $21^{\text {st }}$ Century: The Impact of Bills C-51 (IP21C) and C-52 (IPCEC)

Mackie, M. (1974). Ethnic stereotypes and prejudice: Alberta Indians, Hutterites, and Ukrainians. Canadian Ethnic Studies, 6(1-2), 40-51.

Maeder, E.M. \& Burdett J., (2011). The Combined Effect of Defendant Race and Alleged Gang Affiliation on Mock Juror Decision-Making. Psychiatry, Psychology, and Law. 188-201.

Maeder, E.M., Hunt, J.S., (2011) Talking about a Black Man: The Influence Defendant and Character Witness Race on Juror's Use of Character Evidence. Behavioural Sciences and the Law, 29: 608-620.

Maeder, E., Dempsey, J., \& Pozzulo, J. (2012). Behind the veil of juror decision making: Testing the effects of Muslim veils and defendant race in the courtroom. Criminal Justice and Behavior, 39(5), 666-678.

Maeder, E. M., Yamamoto, S., \& McManus, L. A. (2015). Race salience in Canada: Testing multiple manipulations and target races. Psychology, Public Policy, and Law, 21(4), 442451.

Maeder, E.M., Yamamoto, S., \& Saliba, P. (2015). The influence of defendant race and victim physical attractiveness on juror decision-making in a sexual assault trial. Psychology, Crime, and Law, 21, 62-79.

Maeder, E. M., Yamamoto, S., McManus, L. A. Capaldi, C.A., (2016). Race-crime congruency in the Canadian context. Canadian Journal of Behavioural Science: 162-170. 
Marcus-Newhall, A., Blake, L. P., \& Baumann, J. (2002). Perceptions of hate crime perpetrators and victims as influenced by race, political orientation, and peer group. American Behavioral Scientist, 46(1), 108-135. doi:10.1177/0002764202046001008

Marques, J. M. (1990). The black sheep effect. Outgroup homogeneity in social comparison settings. In D. Abrahams \& M. Hogg (Eds.), Social identity theory: Constructive and critical advances. London, United Kingdom: Harvester Wheatsheaf, p. 131-151.

Marques, J. M., Yzerbyt, V. Y. \& Leyens, J. P. (1988). The "black sheep effect”: Extremity of judgments toward in-group members as a function of group identification. European Journal of Social Psychology, 18, 1-16.

Mazzella, R., \& Feingold, A. (1994). The effects of physical attractiveness, race, socioeconomic status, and gender of defendants and victims on judgments of mock jurors: A meta-analysis. Journal of Applied Social Psychology, 24, 1315-1338.

McGraw-Hill. Jones, C. S., \& Kaplan, M. F. (2003). The effects of racially stereotypical crimes on juror decision-making and information-processing strategies. Basic and Applied Social Psychology, 25, 1-13.

Miller, M.K., \& Bornstein, B.H. (2006). The use of religion in death penalty sentencing trials. Law and Human Behavior, 30 (6), 675-684.

Miller M. K., Maskaly J., Green M., \& Peoples C.D., (2011) The Effects of Deliberations and Religious Identity on Mock Jurors' Verdicts. Group Processes \& Intergroup Relations 14: 517-532. 
Miller, M. K., Maskaly, J., Peoples, C. D., Sigillo, A. E. (2014). The relationship between mock jurors' religious characteristics and their verdicts and sentencing decisions. Psychology of Religion and Spirituality, 6(3), 188-197.

Mitchell, T. L., Haw, R. M., Pfeifer, J. E., \& Meissner, C. A. (2005). Racial bias in mock juror decision-making: A meta-analytic review of defendant treatment. Law and Human Behavior, 29(6), 621-637.

Muhammad v. Paruk, 553 F. Supp. 2 d 893 (2008).

Narby, D. J., Cutler, B. L., \& Moran, G. (1993). A meta-analysis of the association between authoritarianism and jurors' perceptions of defendant culpability. Journal of Applied Psychology, 78(1), 34-42. doi:10.1037/0021-9010.78.1.34

National Judicial Institute. (2011). Model Jury Instructions. Retrieved on May 4th, 2017 from: https://www.nji-inm.ca/index.cfm/publications/model-jury-instructions/

Organization for Security and Co-operation in Europe, (2015). Legal Analysis of the Proposed Bill C-51, the Canadian Anti-Terrorism Act, 2015 Potential Impact on Freedom of Expression. Online at: http://www.osce.org/

Peer, E., Vosgerau, J., \& Acquisti, A. (2014). Reputation as a sufficient condition for data quality on Amazon Mechanical Turk. Behavior Research Methods, 46(4), 1023-1031. doi: $10.3758 / \mathrm{s} 13428-013-0434-y$

Pennington N., Hastie, R., (1988) Explanation-based decision making: The effects of memory structure on judgment. Journal of Experimental Psychology: Learning, Memory, and Cognition, v.14, p.521. 
Pennington N., Hastie, R., (1992), Explaining the evidence: Tests of the story model for juror decision making. Journal of Personality and Social Psychology, v.62, p.189, 1992.

Pennington, N., Hastie, R. (1994). The story model for juror decision making. Cambridge University Press.

Pennington, N., Messamer, P. J., Nicolich, R. (1991). Explanatory coherence in legal decision making. Unpublished manuscript.

Pezdek, K., Avila-Mora, E., \& Sperry, K. (2010). Does trial presentation medium matter in jury simulation research? evaluating the effectiveness of eyewitness expert testimony. Applied Cognitive Psychology, 24(5), 673-690. doi:10.1002/acp.1578

Pfeifer, J. E., \& Bernstein, D. J. (2003). Expressions of modern racism in judgments of others: The role of task and target specificity on attributions of guilt. Social Behavior and Personality, 31, 749-766.

Pfeifer, J.E., Ogloff, J.R., (2003). Mock Juror Ratings of guilt in Canada: Modern Racism and ethnic heritage. Social Behavior and Personality 31(3): 301-12.

Pozzulo, J. D., Dempsey, J., Maeder, E., \& Allen, L. (2010). The effects of victim gender, defendant gender, and defendant age on juror decision making. Criminal Justice and Behavior, 37(1), 47-63. doi:10.1177/0093854809344173

RCMP, (2014). Criminal Threats to Canadian Petroleum Industry. Critical Infrastructure Intelligence Assessment, 2014.

Roach, K., (2002). Canada's New Anti-Terrorism Law. Singapore Journal of Legal Studies, 122148. 
Ruby, C., Hasan, N.R., (2015) Overly broad and unnecessary anti-terrorism reforms could criminalize free speech. Canadian Centre for Policy Alternatives. Retrieved at: https://www.policyalternatives.ca

R. v. N.S., Supreme Court of Canada (2009). O.J. No. 1766.

Sargent, M. J., \& Bradfield, A. L. (2004). Race and information processing in criminal trials: Does the defendant's race affect how the facts are evaluated? Personality and Social Psychology Bulletin, 30, 995-1008.

Shih, M., Pittinsky, T. L., \& Ambady, N. (1999). Stereotype susceptibility: Identity salience and shifts in quantitative performance. Psychological Science, 10(1), 80-83. doi:10.1111/14679280.00111

Skorinko, J. L., \& Spellman, B. A. (2013). Stereotypic crimes: How group-crime associations affect memory and (sometimes) verdicts and sentencing. Victims \& Offenders, 8(3), 278-307. doi:10.1080/15564886.2012.755140

Smith, E. R., \& Zarate, M. A. (1990). Exemplar and prototype use in social categorization. Social Cognition, 8(3), 243-262. doi:10.1521/soco.1990.8.3.243

Sommers, S. R., \& Ellsworth, P. C. (2000). Race in the courtroom: Perceptions of guilt and dispositional attributions. Personality and Social Psychology Bulletin, 26, 1369-1379.

Sommers, S. R. (2006). On racial diversity and group decision making: Identifying multiple effects of racial composition on jury deliberations. Journal of Personality and Social Psychology, 90(4), 597-612. doi:10.1037/0022-3514.90.4.597 
Statistics Canada (2013). National Household Survey (NHS) Profile, 2011 National Household Survey. Statistics Canada Catalogue no. Ottawa. Released September 11, 2013.

Sunnafrank, M., \& Fontes, N. E. (1983). General and crime related racial stereotypes and influence on juridical decisions. Cornell Journal of Social Relations, 17, 1-15.

Sweeney, L. T., \& Haney, C. (1992). The influence of race on sentencing: A meta-analytic review of experimental studies. Behavioral Sciences and the Law, 10, 179-195.

Tait, D. (2011). Deliberating about terrorism: Prejudice and jury verdicts in a mock terrorism trial. Australian \& New Zealand Journal of Criminology, 44(3), 387-403. doi: $10.1177 / 0004865811419067$

Tajfel, H., \& Turner, J. C. (1979). An integrative theory of intergroup conflict. The social psychology of intergroup relations? 33, 47.

Tajfel, H., \& Turner, J. C. (1986). The social identity theory of intergroup behavior. Psychology of intergroup relations. Chicago: Nelson-Hall.

Tang, C. M., \& Nunez, N. (2003). Effects of defendant age and juror bias on judgment of culpability: What happens when a juvenile is tried as an adult? American Journal of Criminal Justice, 28(1), 37-52. doi:10.1007/BF02885751

Tator, C., (2006). Racial profiling in Canada: challenging the myth of "a few bad apples". University of Toronto Press.

Templeton, L. J. \& Hartnagel, T. F. (2012). Causal Attributions of Crime and the Public's Sentencing Goals. Canadian Journal of Criminology and Criminal Justice 54(1), 45-65. University of Toronto Press. 
Thompson, S. B., Merrifield, A., \& Chinnery, H. L. (2011). Are Mock Jurors Influenced by the Defendants Gender, Socio-economic Status and Emotional State in Forensic Medicine? Webmed Central, Forensic Medicine 2(2), doi: 10.9754/journal.wmc.2011.001632

Tumonis, V., Savelskis, M., \& Zalyte, I. (2013). Judicial Decision Making from an Empirical Perspective. Baltic Journal of Law \& Politics 6:1, 140-162.

Unnever, J. D., Cochran J.K., Cullen F.T., \& Applegate, B.K., (2010) The pragmatic American: Attributions of crime and the hydraulic relation hypothesis. Justice Quarterly 27(3): 431-57

Unnever, J. D., Cullen F.T., \& Jones J.D., (2008) Public support for attacking the "root causes" of crime: The impact of egalitarian and racial beliefs. Sociological Focus 41: 1-33.

USA PATRIOT Act, 2001, U.S. H.R. 3162, Public Law 107-56, Title I, Sec. 102

Weiner, B., (1986). An attributional theory of achievement motivation and emotion (pp. 159190). Springer US.

Wiener, R. L., Krauss, D. A., \& Lieberman, J. D. (2011). Mock jury research: Where do we go from here? Behavioral Sciences \& the Law, 29(3), 467-479. doi:10.1002/bs1.989

Willis-Esqueda, C. (1997). European American students' perceptions of crimes committed by five racial groups. Journal of Applied Social Psychology, 27, 1406-1420.

Zafar, S., \& Ross, E. C. (2015). Interreligious contact, attitudes, and stereotypes: A study of five religious groups in Canada. Canadian Journal of Behavioural Science, 47(1), 37-46. 


\section{Appendices}

\section{Appendix A}

\section{Screening Questionnaire}

1) Are you a Canadian citizen?
a. Yes
b. No

2) Do you currently reside in Canada?
a. Yes
b. No

3) Are you 18 years of age or older?
a. Yes
b. No

4) Are you fluent in the English language?
a. Yes
b. No

5) Have you ever been convicted of an indictable offence?
a. Yes
b. No

6) If Yes, have you received a formal pardon?
a. Yes
b. No 


\section{Appendix B}

The defendant is charged with the following:

Every person who, by communicating statements, knowingly advocates, or promotes the commission of terrorism offences in general — other than an offence under this sectionwhile knowing that any of those offences will be committed or being reckless as to whether any of those offences may be committed, as a result of such communication, is guilty of an indictable offence and is liable to imprisonment for a term of not more than five years. (Criminal Code, 2015, s 83.221)

The defendant enters the proceedings presumed to be innocent, and the presumption of innocence remains throughout the case unless the Crown, on the evidence put before you, satisfies you beyond a reasonable doubt that s/he is guilty. Two rules flow from the presumption of innocence. One is that the Crown bears the burden of proving guilt. The other is that guilt must be proved beyond a reasonable doubt. These rules are inextricably linked with the presumption of innocence to ensure that no innocent person is convicted. The burden of proof rests with the Crown and never shifts. There is no burden on the defendant to prove that $\mathrm{s} / \mathrm{he}$ is innocent. S/he does not have to prove anything. This instruction will require modification where the burden of proof is reversed, for example, where the accused denies criminal responsibility on account of mental disorder.

A reasonable doubt is not an imaginary or frivolous doubt. It is not based on sympathy for or prejudice against anyone involved in the proceedings. Rather, it is based on reason and common sense. It is a doubt that arises logically from the evidence or from an absence of evidence. It is 
virtually impossible to prove anything to an absolute certainty, and the Crown is not required to do so. Such a standard would be impossibly high. However, the standard of proof beyond a reasonable doubt falls much closer to absolute certainty than to probable guilt. You must not find the defendant guilty unless you are sure s/he is guilty. Even if you believe that the defendant is probably guilty or likely guilty, that is not sufficient. In those circumstances, you must give the benefit of the doubt to the defendant and find him/her not guilty because the Crown has failed to satisfy you of his/her guilt beyond a reasonable doubt. You must decide, looking at the evidence as a whole, whether the Crown has proved the defendant's guilt beyond a reasonable doubt. If you have a reasonable doubt about the defendant's guilt arising from the evidence, the absence of evidence, or the credibility or the reliability of one or more of the witnesses, then you must find $\operatorname{him} /$ her not guilty. 


\title{
Appendix C
}

The transcripts have been split by the low/medium/high severity levels, as there are significant changes in the dialogue for each. For ease of reading, the components of the dialogue that vary at each level have been highlighted or bolded.

\author{
Pilot Trial Transcript \\ Background Information \\ Charges: Criminal Code of Canada Advocating or promoting the commission of terrorism \\ offences \\ Defendant: Jake Holden
}

\section{Low (No Specific Action Endorsed)}

Crown Opening Statement: Ladies and gentlemen, on the night of September 21, 2016, Parliament was in session and preparing to pass legislation well supported by the Canadian people. A protest had gathered outside, reflecting the opinions of a minority of Canadians. The University Students Association had organized the protest. It was here Jake Holden would incite the public to take actions against the government. Mr. Holden gathered the attention of the protestors and stressed the inability of the peaceful, legal protest to effect any meaningful change, and demanded that they go further. Mr. Holden was not suggesting further peaceful protests, no, the vagueness of Mr. Holden's fervent words can only be construed as encouraging citizens to act illegally, to coerce the broader public to accept their demands. The Crown will present witnesses that clearly recall the radical rhetoric that Mr. Holden was supporting. 
Through this, the Crown will show the defendant's actions increase the risk of a terrorist offence occurring, and we will prove beyond a reasonable doubt that these actions are criminal under advocating or promoting the commission of terrorism offences.

\section{Defence Opening Statement:}

Members of the jury, the Crown will attempt to string together a story of how my client, Jake Holden, is a reckless, radical man whose impassioned rhetoric on September 21, 2016 somehow qualifies as a criminal act. They will present some vague and biased testimony, and hope to couple it together with weak arguments to scare you into thinking Mr. Holden's words created a danger to the public. To the contrary, Mr. Holden is only an enthusiastic participant in politics, who simply exaggerates to make a point. There is no real danger here, and there is no real possibility of harm. Mr. Holden is an innocent man, and the only threat that stands to come out his actions is the concern that the Crown wants to send a productive and active member of the community to prison.

The Crown calls its first witness, Ray Easton, to the stand

Crown: Please state your full name and position for the jury.

Easton: My name is Ray Easton, I work with a security company called the Commissionaires, and I was on duty on September 21, 2016.

Crown: And what were you doing on the night of September 21, 2016 ?

Easton: I was posted as security for the protest occurring outside of Parliament.

Crown: At about what time would this have been? 
Easton: I arrived on site at 1500 hours, and a handful of people had already shown up, the rest appeared by 1530 .

Crown: And did you happen to see the defendant, Jake Holden, at this protest?

Easton: Yes. I don't recall when he showed up, but I noticed him sometime after the protest had begun.

Crown: What drew your attention to Mr. Holden?

Easton: He raised his voice and started to address the assembly, and most people quieted down to listen.

Crown: What happened next?

Easton: He began to talk about Parliament in a pretty negative light. He also spoke about their protest itself, he didn't seem to think that what they were currently doing was going to change anything.

Crown: Can you remember what he said?

Easton: He called the protest useless a number of times. Told them they were wasting their efforts.

Crown: Was there anything more?

Easton: The defendant began suggesting they needed to do more, something that the government and the media couldn't ignore. He didn't provide any real details.

Crown: Can you describe the tone Mr. Holden had as he suggested this?

Easton: Lots of shouting. He seemed angry the whole time, very impassioned.

Crown: Did Mr. Holden clarify what he meant for the people to do?

Easton: No, he was vague. He spent more time talking about how ineffective they were currently being. 
The Defence cross-examines the witness

Defence: Mr. Easton, you say the defendant was being vague. Can you recall any actual statements he made?

Easton: Not really, I wasn't paying that much attention.

Defence: Did you observe any illegal activity following his speech that day?

Easton: Well, no. The protest continued for another hour or so before people began to disperse in a peaceable fashion, sometime around 1700 hours.

Defence: No further questions, your honour.

The Crown calls their second witness, Terry Williams, to the stand.

Crown: Please state your name for the court and your relation to this case.

Williams: My name is Thomas Williams, and I was present at the protest.

Crown: What were you doing on the afternoon of September 21, 2016 ?

Williams: I went to Parliament to join in a protest concerning one of the new bills they were trying to pass.

Crown: Who was at this protest?

Williams: Oh, it was a bunch of us from the University Students Association. We had passed around a letter and got everyone who was available to come along, maybe a couple dozen of us. Crown: How would you describe the nature of your protest?

Williams: Well organized. I know that someone had contacted the police beforehand to notify them we would be there, and where we were going to set up. We brought signs, and there were a 
couple of megaphones going around so we could get a chant going. I think we were doing a good job at getting our message out.

Crown: Do you recall when Mr. Holden began to speak?

Williams: Yeah, it was maybe an hour in. We had been there a while.

Crown: And how would you describe what Mr. Holden was saying, and how he was saying it?

Williams: Oh, well, he said a lot of things.

Crown: Just what you can recall to the best of your memory.

Williams: He spoke at length about how we weren't getting anything done. He brought up the number of protests we'd done in the past, and how nothing had really changed from them. He kept talking about how we needed to do more, or they wouldn't ever take us seriously.

Crown: Can you elaborate on who 'they' were?

Williams: Oh, uh, the government, the media. Just people in general, I suppose.

Crown: Can you elaborate on what he was suggesting?

Williams: Not really. He didn't mention anything but he was upset that we weren't trying anything new. He said he wanted us to do something that couldn't be ignored.

Crown: How would you describe Mr. Holden's temperament on that day?

Williams: Angry, like he was looking for a fight.

Crown: Thank you Mr. Williams, that is all.

The Defence cross-examines Thomas Williams

Defence: You say you were at the protest on September 21, 2016 ?

Williams: Yes sir, that's correct.

Defence: Was this the first time you had seen Mr. Holden? 
Williams: Uh, no, no. I know him a little. I've seen him at protests before.

Defence: How would you describe your relationship with him?

Williams: Not good? We don't agree on much. We've gotten in a couple of arguments.

Defence: Thank you, that is all.

The Defence calls their witness, Charles Thompson to the stand

Defence: Mr. Thompson, what were you doing on September 21, 2016 ?

Thompson: I was up on Parliament, I was part of the protest as well.

Defence: How long have you been a member of the group hosting the protest?

Thompson: A few years now. I joined back in 2014.

Defence: Did you see Mr. Holden on September 21, $2016 ?$

Thompson: Yes, there weren't many of us at the protest, he was hard to miss.

Defence: Can you describe what Mr. Holden's temperament was like on that day?

Thompson: Frustrated, fed up with people ignoring us.

Defence: Do you recall Mr. Holden asking you to do anything illegal?

Thompson: No, of course not. He was just annoyed at the bill going through.

Defence: Did you or any other member of your protest go out and do anything illegal following

Mr. Holden's speech?

Thompson: No.

Defence: So, Mr. Holden expressed nothing more than a bit of irritation, and no one took it to mean anything else. Thank you. 
Crown: You have been a member of the protest group for several years?

Thompson: Yes, I have.

Crown: Have you, or the group ever done anything illegal in the past?

Thompson: I believe we trespassed once, but otherwise no.

Crown: Did Mr. Holden suggest a further legal course of action for the group to take?

Thompson: No.

Crown: So, Mr. Holden made no explicit suggestion for what you should do. He merely lamented the ineffectiveness of every legal option, and left you to do draw your own conclusions?

Thompson: Well, yes.

Crown: Thank you Mr. Thompson, that is all.

Crown Closing Statement: Ladies and gentlemen, Jake Holden was at a peaceful protest on September 21, 2016, when he decided that the perfectly legal and reasonable display of disagreement put on by his fellow protestors wasn't enough. Instead of organizing a wider protest, or convincing people to join his cause, Mr. Holden begin to spout rhetoric that demanded more. It is clear from the language he used, and his anger at legal alternatives, that Mr. Holden intended to encourage his fellow citizens towards illegal activity to coerce the Canadian public. Mr. Holden was looking to go beyond the law to find 'something that couldn't be ignored'. This is precisely the type of advocacy that section 83.221 of the Canadian Criminal Code seeks to restrict for the danger it poses. His actions are not in contention, and as members of the jury, it is your duty to find Mr. Holden guilty. 
Defence Closing Statement: Jake Holden is simply a man that grew frustrated with the political process. On September 21, 2016, Mr. Holden did nothing more than vent this frustration to his peers, and any insinuation further is reaching. Mr. Holden did not ask anyone to do anything illegal, let alone advocate for any action that could be called terrorism. Accordingly, nothing illegal has come out of the group he was speaking to, and he carried out no illegal activity himself. He was passionate, because he's passionate about his cause. There's no reason to be found in any of the testimony provided that Mr. Holden could pose a threat to the public, or that his words would create one. Applying the Criminal Code in this instance is a far overreach of the law's intention, and would only serve to send an innocent man to jail.

Crown Rebuttal: We have a witness who has described the defendant asking for more than legal protest. He kept his words vague, and let the subtle implication carry what we wanted to see out of his peers. Make no mistake, when Jake Holden requested members of a peaceful, legally held protest to do more, to do something that couldn't be ignored, he wasn't advocating that they host more peaceful protests. It is clear that Mr. Holden was promoting the use of illegal alternatives, that can only fall under terrorism offences in general. This is not acceptable speech in Canadian society, and you can make that statement by finding the defendant, Jake Holden guilty. 


\section{Medium (Forming of Militia-like groups)}

Crown Opening Statement: Ladies and gentlemen, on the night of September 21, 2016, Parliament was in session and preparing to pass legislation well supported by the Canadian people. A protest had gathered outside, reflecting the opinions of a minority of Canadians. The University Students Association had organized the protest. It was here Jake Holden would incite the public to take actions against the government. Mr. Holden gathered the attention of the protestors and stressed the inability of the peaceful, legal protest to effect any meaningful change, and demanded that they go further. Mr. Holden was not suggesting further peaceful protests, no, Mr. Holden encouraged the public to prepare against further legislation through arming themselves, and stockpiling resources. Mr. Holden's lack of explicit directions as to what citizens would do with these preparations was immaterial, as there could be no intended legal use. The Crown will present witnesses that clearly recall the radical rhetoric that $\mathbf{M r}$. Holden was supporting. Through this, the Crown will show the defendant's actions increase the risk of a terrorist offence occurring, and we will prove beyond a reasonable doubt that these actions are criminal under advocating or promoting the commission of terrorism offences.

\section{Defence Opening Statement:}

Members of the jury, the Crown will attempt to string together a story of how my client, Jake Holden, is a reckless, radical man whose impassioned rhetoric on September 21, 2016 somehow qualifies as a criminal act. They will present some vague and biased testimony, and hope to couple it together with weak arguments to scare you into thinking Mr. Holden's words created a danger to the public. To the contrary, Mr. Holden is only an enthusiastic participant in politics, 
who simply exaggerates to make a point. There is no real danger here, and there is no real possibility of harm. Mr. Holden is an innocent man, and the only threat that stands to come out his actions is the concern that the Crown wants to send a productive and active member of the community to prison.

The Crown calls its first witness, Ray Easton, to the stand

Crown: Please state your full name and position for the jury.

Easton: My name is Ray Easton, I work with a security company called the Commissionaires, and I was on duty on September 21, 2016.

Crown: And what were you doing on the night of September 21, 2016 ?

Easton: I was posted as security for the protest occurring outside of Parliament.

Crown: At about what time would this have been?

Easton: I arrived on site at 1500 hours, and a handful of people had already shown up, the rest appeared by 1530 .

Crown: And did you happen to see the defendant, Jake Holden, at this protest?

Easton: Yes. I don't recall when he showed up, but I noticed him sometime after the protest had begun.

Crown: What drew your attention to Mr. Holden?

Easton: He raised his voice and started to address the assembly, and most people quieted down to listen.

Crown: What happened next? 
Easton: He began to talk about Parliament in a pretty negative light. He also spoke about their protest itself, he didn't seem to think that what they were currently doing was going to change anything.

Crown: Can you remember what he said?

Easton: He called the protest useless a number of times. Told them they were wasting their efforts.

Crown: Was there anything more?

Easton: The defendant began suggesting they needed to begin stockpiling resources, things like food and even weapons.

Crown: Can you describe the tone Mr. Holden had as he suggested this?

Easton: Lots of shouting. He seemed angry the whole time, very impassioned.

Crown: Did Mr. Holden clarify what he meant for the people to do with these stockpiles?

Easton: No, he was vague, just they needed to 'prepare'. He spent more time talking about how ineffective they were currently being.

The Defence cross-examines the witness

Defence: Mr. Easton, you say the defendant was being vague. Can you recall any actual statements he made?

Easton: Not really, I wasn't paying that much attention.

Defence: Do you recall Mr. Holden suggesting any specific illegal activity?

Easton: No, nothing specific.

Defence: Did you observe any illegal activity following his speech that day? 
Easton: Well, no. The protest continued for another hour or so before people began to disperse in a peaceable fashion, sometime around 1700 hours.

Defence: No further questions, your honour.

The Crown calls their second witness, Terry Williams, to the stand.

Crown: Please state your name for the court and your relation to this case.

Williams: My name is Thomas Williams, and I was present at the protest.

Crown: What were you doing on the afternoon of September 21, 2016?

Williams: I went to Parliament to join in a protest concerning one of the new bills they were trying to pass.

Crown: Who was at this protest?

Williams: Oh, it was a bunch of us from the University Students Association. We had passed around a letter and got everyone who was available to come along, maybe a couple dozen of us. Crown: How would you describe the nature of your protest?

Williams: Well organized. I know that someone had contacted the police beforehand to notify them we would be there, and where we were going to set up. We brought signs, and there were a couple of megaphones going around so we could get a chant going. I think we were doing a good job at getting our message out.

Crown: Do you recall when Mr. Holden began to speak?

Williams: Yeah, it was maybe an hour in. We had been there a while.

Crown: And how would you describe what Mr. Holden was saying, and how he was saying it? Williams: Oh, well, he said a lot of things.

Crown: Just what you can recall to the best of your memory. 
Williams: He spoke at length about how we weren't getting anything done. He brought up the number of protests we'd done in the past, and how nothing had really changed from them. He kept talking about how we needed to do more, or they wouldn't ever take us seriously.

Crown: Can you elaborate on who 'they' were?

Williams: Oh, uh, the government, the media. Just people in general, I suppose.

Crown: Can you elaborate on what he was suggesting?

Williams: He wanted us to begin 'preparing'. He recommended people start looking into gun licenses, and putting together food and supplies. He described it as a sort of militia, like some of the ones have down in the United States.

Crown: How would you describe Mr. Holden's temperament on that day?

Williams: Angry, like he was looking for a fight.

Crown: Thank you Mr. Williams, that is all.

The Defence cross-examines Thomas Williams

Defence: You say you were at the protest on September 21, 2016?

Williams: Yes sir, that's correct.

Defence: Was this the first time you had seen Mr. Holden?

Williams: Uh, no, no. I know him a little. I've seen him at protests before.

Defence: How would you describe your relationship with him?

Williams: Not good? We don't agree on much. We've gotten in a couple of arguments.

Defence: Did Mr. Holden in any direct terms ever actually suggest getting in a fight with anyone?

Williams: Well, no. No, he did not. 
Defence: Thank you, that is all.

The Defence calls their witness, Charles Thompson to the stand

Defence: Mr. Thompson, what were you doing on September 21, 2016 ?

Thompson: I was up on Parliament, I was part of the protest as well.

Defence: How long have you been a member of the group hosting the protest?

Thompson: A few years now. I joined back in 2014.

Defence: Did you see Mr. Holden on September 21, $2016 ?$

Thompson: Yes, there weren't many of us at the protest, he was hard to miss.

Defence: Can you describe what Mr. Holden's temperament was like on that day?

Thompson: Frustrated, fed up with people ignoring us.

Defence: Do you recall Mr. Holden asking you to do anything illegal?

Thompson: No, of course not. He was just annoyed at the bill going through.

Defence: Did you or any other member of your protest go out and do anything illegal following

Mr. Holden's speech?

Thompson: No.

Defence: So, Mr. Holden expressed nothing more than a bit of irritation, and no one took it to mean anything else. Thank you.

The Crown cross-examines Mike Thompson

Crown: You have been a member of the protest group for several years?

Thompson: Yes, I have.

Crown: Have you, or the group ever done anything illegal in the past? 
Thompson: I believe we trespassed once, but otherwise no.

Crown: Did Mr. Holden suggest what he wanted people to do with these weapons and supplies? Thompson: Well, he mentioned movements like the Black Panther Party, and some of the militias down in the United States. He seemed to want to make something like that.

Crown: So, Mr. Holden made no explicit suggestion for what you should do with these weapons. He simply provided a number of violent movements as example, and left you to draw your own conclusions?

Thompson: Well, yes.

Crown: Thank you Mr. Thompson, that is all.

Crown Closing Statement: Ladies and gentlemen, Jake Holden was at a peaceful protest on September 21, 2016, when he decided that the perfectly legal and reasonable display of disagreement put on by his fellow protestors wasn't enough. Instead of organizing a wider protest, or convincing people to join his cause, Mr. Holden begin to spout rhetoric that demanded more. It is clear from the rhetoric he used, and the intention to collect weapons, that Mr. Holden did not intended to encourage his fellow citizens towards further peaceful protests, Mr. Holden was looking to go beyond the law to find 'something that couldn't be ignored'. He wanted to prepare the group to be able to intimidate and coerce. This is precisely the type of advocacy that section 83.221 of the Canadian Criminal Code seeks to restrict for the danger it poses. His actions are not in contention, and as members of the jury, it is your duty to find Mr. Holden guilty. 
Defence Closing Statement: Jake Holden is simply a man that grew frustrated with the political process. On September 21, 2016, Mr. Holden did nothing more than vent this frustration to his peers, and any insinuation further is reaching. Mr. Holden did not ask anyone to do anything illegal, let alone advocate for any action that could be called terrorism. Accordingly, nothing illegal has come out of the group he was speaking to, and he carried out no illegal activity himself. He was passionate, because he's passionate about his cause. There's no reason to be found in any of the testimony provided that Mr. Holden could pose a threat to the public, or that his words would create one. Owning a licensed gun is perfectly legal in Canada, as is forming a movement. The prosecution would have you convict a man for advocating perfectly legal things based on fear mongering that they might be used another way. Applying the Criminal Code in this instance is a far overreach of the law's intention, and would only serve to send an innocent man to jail.

Crown Rebuttal: We have a witness who has described the defendant asking for more than legal protest. He kept his words vague, and let the subtle implication carry what we wanted to see out of his peers. Make no mistake, when Jake Holden requested members of a peaceful, legally held protest to do more, to gather weapons and stockpile resources, he wasn't advocating that they host more peaceful protests. It is clear that Mr. Holden was promoting the use of illegal alternatives, intimidation and coercion, that can only fall under terrorism offences in general. This is not acceptable speech in Canadian society, and you can make that statement by finding the defendant, Jake Holden guilty. 


\section{High (Riot/Violence)}

Crown Opening Statement: Ladies and gentlemen, on the night of September 21, 2016, Parliament was in session and preparing to pass legislation well supported by the Canadian people. A protest had gathered outside, reflecting the opinions of a minority of Canadians. The University Students Association had organized the protest. It was here Jake Holden would incite the public to take actions against the government. Mr. Holden gathered the attention of the protestors and stressed the inability of the peaceful, legal protest to effect any meaningful change, and demanded that they go further. Mr. Holden was not suggesting further peaceful protests, no, Mr. Holden explicitly encouraged violence. Mr. Holden told the crowd that their current methods would not change the public's opinion, and that only riots had ever brought the media's attention to their cause. He actively encouraged the other protestors towards property damage and assault. The Crown will present witnesses that clearly recall the radical rhetoric that Mr. Holden was supporting. Through this, the Crown will show the defendant's actions increase the risk of a terrorist offence occurring, and we will prove beyond a reasonable doubt that these actions are criminal under advocating or promoting the commission of terrorism offences.

\section{Defence Opening Statement:}

Members of the jury, the Crown will attempt to string together a story of how my client, Jake Holden, is a reckless, radical man whose impassioned rhetoric on September 21, 2016 somehow qualifies as a criminal act. They will present some vague and biased testimony, and hope to couple it together with weak arguments to scare you into thinking Mr. Holden's words would lead to terrorism. To the contrary, Mr. Holden is only an enthusiastic participant in politics, who 
simply exaggerates to make a point. There is no real danger here, and there is no real possibility of harm. Mr. Holden is an innocent man, and the only threat that stands to come out his actions is the concern that the Crown wants to send a productive and active member of the community to prison.

The Crown calls its first witness, Ray Easton, to the stand

Crown: Please state your full name and position for the jury.

Easton: My name is Ray Easton, I work with a security company called the Commissionaires, and I was on duty on September 21, 2016.

Crown: And what were you doing on the night of September 21, 2016 ?

Easton: I was posted as security for the protest occurring outside of Parliament.

Crown: At about what time would this have been?

Easton: I arrived on site at 1500 hours, and a handful of people had already shown up, the rest appeared by 1530 .

Crown: And did you happen to see the defendant, Jake Holden, at this protest?

Easton: Yes. I don't recall when he showed up, but I noticed him sometime after the protest had begun.

Crown: What drew your attention to Mr. Holden?

Easton: He raised his voice and started to address the assembly, and most people quieted down to listen.

Crown: What happened next? 
Easton: He began to talk about Parliament in a pretty negative light. He also spoke about their protest itself, he didn't seem to think that what they were currently doing was going to change anything.

Crown: Can you remember what he said?

Easton: He called the protest useless a number of times. Told them they were wasting their efforts.

Crown: Was there anything more?

Easton: The defendant began suggesting they needed to do more, he started talking about how the media only ever pays attention when folks begin to riot. That they just ignore quiet protests. Crown: Can you describe the tone Mr. Holden had as he suggested this?

Easton: Lots of shouting. He seemed angry the whole time, very impassioned.

Crown: Did Mr. Holden clarify what he meant for the people to do?

Easton: He said people needed to get up in arms over the new bill, that they needed to take to the streets and get violent if needed.

Crown: Thank you.

The Defence cross-examines the witness

Defence: Mr. Easton, you say the defendant was being vague. Can you recall any actual statements he made?

Easton: Not really, I wasn't paying enough attention to quote him.

Defence: Did you observe any actual illegal activity following his speech that day?

Easton: Well, no. The protest continued for another hour or so before people began to disperse in a peaceable fashion, sometime around 1700 hours. 
Defence: No further questions, your honour.

The Crown calls their second witness, Terry Williams, to the stand.

Crown: Please state your name for the court and your relation to this case.

Williams: My name is Thomas Williams, and I was present at the protest.

Crown: What were you doing on the afternoon of September 21, 2016?

Williams: I went to Parliament to join in a protest concerning one of the new bills they were trying to pass.

Crown: Who was at this protest?

Williams: Oh, it was a bunch of us from the University Students Association. We had passed around a letter and got everyone who was available to come along, maybe a couple dozen of us. Crown: How would you describe the nature of your protest?

Williams: Well organized. I know that someone had contacted the police beforehand to notify them we would be there, and where we were going to set up. We brought signs, and there were a couple of megaphones going around so we could get a chant going. I think we were doing a good job at getting our message out.

Crown: Do you recall when Mr. Holden began to speak?

Williams: Yeah, it was maybe an hour in. We had been there a while.

Crown: And how would you describe what Mr. Holden was saying, and how he was saying it?

Williams: Oh, well, he said a lot of things.

Crown: Just what you can recall to the best of your memory. 
Williams: He spoke at length about how we weren't getting anything done. He brought up the number of protests we'd done in the past, and how nothing had really changed from them. He kept talking about how we needed to do more, or they wouldn't ever take us seriously.

Crown: Can you elaborate on who 'they' were?

Williams: Oh, uh, the government, the media. Just people in general, I suppose.

Crown: Can you elaborate on what he was suggesting?

Williams: He wanted to get a riot going, smash up some stores if necessary. He didn't think anything less would get the media's attention, and until we managed to get on the news no one was going to care about our movement.

Crown: How would you describe Mr. Holden's temperament on that day?

Williams: Angry, like he was looking for a fight.

Crown: Thank you Mr. Williams, that is all.

The Defence cross-examines Thomas Williams

Defence: You say you were at the protest on September 21, 2016?

Williams: Yes sir, that's correct.

Defence: Was this the first time you had seen Mr. Holden?

Williams: Uh, no, no. I know him a little. I've seen him at protests before.

Defence: How would you describe your relationship with him?

Williams: Not good? We don't agree on much. We've gotten in a couple of arguments.

Defence: Thank you, that is all.

The Defence calls their witness, Charles Thompson to the stand 
Defence: Mr. Thompson, what were you doing on September 21, 2016 ?

Thompson: I was up on Parliament, I was part of the protest as well.

Defence: How long have you been a member of the group hosting the protest?

Thompson: A few years now. I joined back in 2014.

Defence: Did you see Mr. Holden on September 21, 2016 ?

Thompson: Yes, there weren't many of us at the protest, he was hard to miss.

Defence: Can you describe what Mr. Holden's temperament was like on that day?

Thompson: Frustrated, fed up with people ignoring us.

Defence: Do you recall Mr. Holden asking you to do anything illegal?

Thompson: Yes, he went on a rant that day, started calling for people to riot and fight back.

Defence: Did you or any other member of your protest go out and do anything illegal following

Mr. Holden's speech?

Thompson: No, of course not.

Defence: Can you explain why not?

Thompson: Well, he was just ranting and carrying on. People do that every now and then. No one was actually going to go fight people and flip cars over.

Defence: So, Mr. Holden expressed nothing more than a bit of irritation, and no one took it to mean anything else. Thank you.

\section{The Crown cross-examines Mike Thompson}

Crown: You have been a member of the protest group for several years?

Thompson: Yes, I have.

Crown: Have you, or the group ever done anything illegal in the past? 
Thompson: I believe we trespassed once, but otherwise no.

Crown: Did you directly hear Mr. Holden suggest the riot?

Thompson: Yes.

Crown: Did you believe Mr. Holden to be joking, or insincere in his encouragement?

Thompson: No, he was serious about it.

Crown: And you didn't go riot. We were lucky that you and the other members of the protest were far more reasonable than Mr. Holden. Thank you, that is all.

Crown Closing Statement: Ladies and gentlemen, Jake Holden was at a peaceful protest on September 21, 2016, when he decided that the perfectly legal and reasonable display of disagreement put on by his fellow protestors wasn't enough. Instead of organizing a wider protest, or convincing people to join his cause, Mr. Holden begin to spout rhetoric that demanded more. It is clear from the language he used, and his anger at legal alternatives, that Mr. Holden intended to encourage his fellow citizens towards rioting and violence, in an effort to coerce the Canadian public. The other protestors rightly disregarded this suggestion, but that does not change the fact that Mr. Holden sought to encourage his fellow protestors to riot, to intimidate a public he felt was ignoring them. His mere incompetence in convincing others to do this doesn't absolve him of the act. This is precisely the type of advocacy that section 83.221 of the Canadian Criminal Code seeks to restrict for the danger it poses. His actions are not in contention, and as members of the jury, it is your duty to find Mr. Holden guilty.

Defence Closing Statement: Jake Holden is simply a man that grew frustrated with the political process. On September 21, 2016, Mr. Holden did nothing more than vent this 
frustration to his peers, and any insinuation further is reaching. Mr. Holden grew briefly irrational and suggested rioting, but nothing came of this rhetoric. Nothing illegal has come out of the group he was speaking to, and he carried out no illegal activity himself. He was passionate, because he's passionate about his cause. There's no reason to be found in any of the testimony provided that Mr. Holden could pose a threat to the public, or that his words would create one. Applying the Criminal Code in this instance is a far overreach of the law's intention, and would only serve to send an innocent man to jail.

Crown Rebuttal: We have a witness who has described the defendant asking for more than legal protest. He explicitly encouraged violence and rioting. Make no mistake, when Jake Holden requested members of a peaceful, legally held protest to riot, to take to the streets in violence, he wasn't merely letting off steam. It is clear that Mr. Holden was promoting the use of illegal alternatives that can only fall under terrorism offences in general. He wanted to turn a peaceful protest into a violent group that could intimidate the Canadian public into accepting their demands. This is not acceptable speech in Canadian society, and you can make that statement by finding the defendant, Jake Holden guilty. 


\section{Main Study Trial Transcript}

Background Information

Charges: Criminal Code of Canada Advocating or promoting the commission of terrorism offences

Defendant: Jake Holden/Samir Bahar/Will Borden

Crown Opening Statement: Ladies and gentlemen, on the night of September 21, 2016, Parliament was in session and preparing to pass legislation well supported by the Canadian people. A protest had gathered outside, reflecting the opinions of a minority of Canadians/a minority of Christian Canadians/a minority of Muslim Canadians. The University Students Association/Christian University Students Association/Muslim University Students Association had organized the protest. It was here Jake Holden/Samir Bahar/Will Borden would incite the public to take actions against the government. Mr. Holden/Mr. Bahar/Mr. Borden gathered the attention of the protestors and stressed the inability of the peaceful, legal protest to effect any meaningful change, and demanded that they go further. Mr. Holden/Mr. Bahar/Mr. Borden was not suggesting further peaceful protests, no, Mr. Holden/Mr. Bahar/Mr. Borden encouraged the public to prepare against further legislation through arming themselves, and stockpiling resources. Mr. Holden/Mr. Bahar/Mr. Borden's lack of explicit directions as to what citizens would do with these preparations was immaterial, as there could be no intended legal use. The Crown will present witnesses that clearly recall the radical rhetoric that Mr. Holden/Mr. Bahar/Mr. Borden was supporting. Through this, the Crown will show the defendant's actions increase the risk of a terrorist offence occurring, and we will prove 
beyond a reasonable doubt that these actions are criminal under advocating or promoting the commission of terrorism offences.

\section{Defence Opening Statement:}

Members of the jury, the Crown will attempt to string together a story of how my client, Jake Holden/Samir Bahar/Will Borden, is a reckless, radical man whose impassioned rhetoric on September 21, 2016 somehow qualifies as a criminal act. They will present some vague and biased testimony, and hope to couple it together with weak arguments to scare you into thinking Mr. Holden/Mr. Bahar/Mr. Borden's words created a danger to the public. To the contrary, Mr. Holden/Mr. Bahar/Mr. Borden is only an enthusiastic participant in politics, who simply exaggerates to make a point. There is no real danger here, and there is no real possibility of harm. Mr. Holden/Mr. Bahar/Mr. Borden is an innocent man, and the only threat that stands to come out his actions is the concern that the Crown wants to send a productive and active member of the community to prison.

The Crown calls its first witness, Ray Easton, to the stand

Crown: Please state your full name and position for the jury.

Easton: My name is Ray Easton, I work with a security company called the Commissionaires, and I was on duty on September 21, 2016.

Crown: And what were you doing on the night of September 21, 2016 ?

Easton: I was posted as security for the protest occurring outside of Parliament. 
Crown: At about what time would this have been?

Easton: I arrived on site at 1500 hours, and a handful of people had already shown up, the rest appeared by 1530 .

Crown: And did you happen to see the defendant, Jake Holden/Samir Bahar/Will Borden, at this protest?

Easton: Yes. I don't recall when he showed up, but I noticed him sometime after the protest had begun.

Crown: What drew your attention to Mr. Holden/Mr. Bahar/Mr. Borden?

Easton: He raised his voice and started to address the assembly, and most people quieted down to listen.

Crown: What happened next?

Easton: He began to talk about Parliament in a pretty negative light. He also spoke about their protest itself, he didn't seem to think that what they were currently doing was going to change anything.

Crown: Can you remember what he said?

Easton: He called the protest useless a number of times. Told them they were wasting their efforts.

Crown: Was there anything more?

Easton: The defendant began suggesting they needed to begin stockpiling resources, things like food and even weapons.

Crown: Can you describe the tone Mr. Holden/Mr. Bahar/Mr. Borden had as he suggested this?

Easton: Lots of shouting. He seemed angry the whole time, very impassioned. 
Crown: Did Mr. Holden/Mr. Bahar/Mr. Borden clarify what he meant for the people to do with these stockpiles?

Easton: No, he was vague, just they needed to 'prepare'. He spent more time talking about how ineffective they were currently being.

The Defence cross-examines the witness

Defence: Mr. Easton, you say the defendant was being vague. Can you recall any actual statements he made?

Easton: Not really, I wasn't paying that much attention.

Defence: Do you recall Mr. Holden/Mr. Bahar/Mr. Borden suggesting any specific illegal activity?

Easton: No, nothing specific.

Defence: Did you observe any illegal activity following his speech that day?

Easton: Well, no. The protest continued for another hour or so before people began to disperse in a peaceable fashion, sometime around 1700 hours.

Defence: No further questions, your honour.

The Crown calls their second witness, Thomas Williams, to the stand.

Crown: Please state your name for the court and your relation to this case.

Williams: My name is Thomas Williams, and I was present at the protest.

Crown: What were you doing on the afternoon of September 21, 2016 ?

Williams: I went to Parliament to join in a protest concerning one of the new bills they were trying to pass. 
Crown: Who was at this protest?

Williams: Oh, it was a bunch of us from the University Students Association/Muslim University Students Association/Christian University Students Association. We had passed around a letter and got everyone who was available to come along, maybe a couple dozen of us.

Crown: How would you describe the nature of your protest?

Williams: Well organized. I know that someone had contacted the police beforehand to notify them we would be there, and where we were going to set up. We brought signs, and there were a couple of megaphones going around so we could get a chant going. I think we were doing a good job at getting our message out.

Crown: Do you recall when Mr. Holden/Mr. Bahar/Mr. Borden began to speak?

Williams: Yeah, it was maybe an hour in. We had been there a while.

Crown: And how would you describe what Mr. Holden/Mr. Bahar/Mr. Borden was saying, and how he was saying it?

Williams: Oh, well, he said a lot of things.

Crown: Just what you can recall to the best of your memory.

Williams: He spoke at length about how we weren't getting anything done. He brought up the number of protests we'd done in the past, and how nothing had really changed from them. He kept talking about how we needed to do more, or they wouldn't ever take us seriously.

Crown: Can you elaborate on who 'they' were?

Williams: Oh, uh, the government, the media. Just people in general, I suppose.

Crown: Can you elaborate on what he was suggesting? 
Williams: He wanted us to begin 'preparing'. He recommended people start looking into gun licenses, and putting together food and supplies. He described it as a sort of militia, like some of the ones have down in the United States.

Crown: How would you describe Mr. Holden/Mr. Bahar/Mr. Borden's temperament on that day?

Williams: Angry, like he was looking for a fight.

Crown: Thank you Mr. Williams, that is all.

The Defence cross-examines Thomas Williams

Defence: You say you were at the protest on September 21, 2016?

Williams: Yes sir, that's correct.

Defence: Was this the first time you had seen Mr. Holden/Mr. Bahar/Mr. Borden?

Williams: Uh, no, no. I know him a little. I've seen him at protests before.

Defence: How would you describe your relationship with him?

Williams: Not good? We don't agree on much. We've gotten in a couple of arguments.

Defence: Did Mr. Holden/Mr. Bahar/Mr. Borden in any direct terms ever actually suggest getting in a fight with anyone?

Williams: Well, no. No, he did not.

Defence: Thank you, that is all.

The Defence calls their witness, Mike Thompson to the stand

Defence: Please state your name for the court and your relation to this case. 
Thompson: My name is Mike Thompson, and I'm part of the University Students Association/Muslim University Students Association/Christian University Students Association.

Defence: Mr. Thompson, what were you doing on September 21, 2016 ?

Thompson: I was up on Parliament, I was part of the protest as well.

Defence: How long have you been a member of the group hosting the protest?

Thompson: A few years now. I joined back in 2014.

Defence: Did you see Mr. Holden/Mr. Bahar/Mr. Borden on September 21, 2016 ?

Thompson: Yes, there weren't many of us at the protest, he was hard to miss.

Defence: Can you describe what Mr. Holden/Mr. Bahar/Mr. Borden's temperament was like on that day?

Thompson: Frustrated, fed up with people ignoring us.

Defence: Do you recall Mr. Holden/Mr. Bahar/Mr. Borden asking you to do anything illegal? Thompson: No, of course not. He was just annoyed at the bill going through.

Defence: Did you or any other member of your protest go out and do anything illegal following Mr. Holden/Mr. Bahar/Mr. Borden's speech?

Thompson: No.

Defence: So, Mr. Holden/Mr. Bahar/Mr. Borden expressed nothing more than a bit of irritation, and no one took it to mean anything else. Thank you.

The Crown cross-examines Mike Thompson

Crown: You have been a member of the protest group for several years?

Thompson: Yes, I have. 
Crown: Have you, or the group ever done anything illegal in the past?

Thompson: I believe we trespassed once, but otherwise no.

Crown: Did Mr. Holden/Mr. Bahar/Mr. Borden suggest what he wanted people to do with these weapons and supplies?

Thompson: Well, he mentioned movements like the Black Panther Party, and some of the militias down in the United States. He seemed to want to make something like that.

Crown: So, Mr. Holden/Mr. Bahar/Mr. Borden made no explicit suggestion for what you should do with these weapons. He simply provided a number of violent movements as example, and left you to draw your own conclusions?

Thompson: Well, yes.

Crown: Thank you Mr. Thompson, that is all.

Crown Closing Statement: Ladies and gentlemen, Jake Holden/Samir Bahar/Will Borden was at a peaceful protest on September 21,2016, when he decided that the perfectly legal and reasonable display of disagreement put on by his fellow protestors wasn't enough. Instead of organizing a wider protest, or convincing people to join his cause, Mr. Holden/Mr. Bahar/Mr. Borden begin to spout rhetoric that demanded more. It is clear from the rhetoric he used, and the intention to collect weapons, that Mr. Holden/Mr. Bahar/Mr. Borden did not intended to encourage his fellow citizens towards further peaceful protests, Mr. Holden/Mr. Bahar/Mr. Borden was looking to go beyond the law to find 'something that couldn't be ignored'. He wanted to prepare the group to be able to intimidate and coerce. This is precisely the type of advocacy that section 83.221 of the Canadian Criminal Code seeks to restrict for the danger it 
poses. His actions are not in contention, and as members of the jury, it is your duty to find Mr.

Holden/Mr. Bahar/Mr. Borden guilty.

Defence Closing Statement: Jake Holden/Samir Bahar/Will Borden is simply a man that grew frustrated with the political process. On September 21, 2016, Mr. Holden/Mr. Bahar/Mr. Borden did nothing more than vent this frustration to his peers, and any insinuation further is reaching. Mr. Holden/Mr. Bahar/Mr. Borden did not ask anyone to do anything illegal, let alone advocate for any action that could be called terrorism. Accordingly, nothing illegal has come out of the group he was speaking to, and he carried out no illegal activity himself. He was passionate, because he's passionate about his cause. There's no reason to be found in any of the testimony provided that Mr. Holden/Mr. Bahar/Mr. Borden could pose a threat to the public, or that his words would create one. Owning a licensed gun is perfectly legal in Canada, as is forming a movement. The prosecution would have you convict a man for advocating perfectly legal things based on fear mongering that they might be used another way. Applying the Criminal Code in this instance is a far overreach of the law's intention, and would only serve to send an innocent man to jail.

Crown Rebuttal: We have a witness who has described the defendant asking for more than legal protest. He kept his words vague, and let the subtle implication carry what we wanted to see out of his peers. Make no mistake, when Jake Holden/Samir Bahar/Will Borden requested members of a peaceful, legally held protest to do more, to gather weapons and stockpile resources, he wasn't advocating that they host more peaceful protests. It is clear that Mr. Holden/Mr. Bahar/Mr. Borden was promoting the use of illegal alternatives, intimidation and 
coercion, that can only fall under terrorism offences in general. This is not acceptable speech in Canadian society, and you can make that statement by finding the defendant, Jake Holden/Samir Bahar/Will Borden guilty. 


\section{Appendix D}

1. How do you find the defendant with regards to Advocating or Promoting the Commission of Terrorism Offences?

Guilty

Not Guilty 
2. If the other protestors had decided to follow Mr. Holden's advice, and carried out his suggested strategy, how severe would you rate the actions they would have taken?

\section{Severity of Action}

Not at all Severe

Very Severe

$\begin{array}{llllllllllll}\text { How severe would } & 1 & 2 & 3 & 4 & 5 & 6 & 7 & 8 & 9 \\ \text { you consider the } \\ \text { action that Mr. } \\ \text { Holden suggested? }\end{array}$




\section{Appendix E}

2. Below is a list of adjectives. We would like you to indicate the degree to which the words below represent part of the cultural stereotype of White Canadians/Black Canadians/Arab Canadians/Christian Canadians/Muslim Canadians/Canadians (what is the culturally-held stereotype about this group, NOT your personal beliefs). Asterisks denote reverse coded adjectives.

Not at all

Very Much

Cultural Stereotypes

\begin{tabular}{|c|c|c|c|c|c|c|}
\hline Honest* & 1 & 2 & 3 & 4 & 5 & 6 \\
\hline Deceitful & 1 & 2 & 3 & 4 & 5 & 6 \\
\hline Radical & 1 & 2 & 3 & 4 & 5 & 6 \\
\hline Faithful* & 1 & 2 & 3 & 4 & 5 & 6 \\
\hline Suspicious & 1 & 2 & 3 & 4 & 5 & 6 \\
\hline Uneducated & 1 & 2 & 3 & 4 & 5 & 6 \\
\hline Courteous* & 1 & 2 & 3 & 4 & 5 & 6 \\
\hline Impulsive & 1 & 2 & 3 & 4 & 5 & 6 \\
\hline Hostile & 1 & 2 & 3 & 4 & 5 & 6 \\
\hline Ambitious* & 1 & 2 & 3 & 4 & 5 & 6 \\
\hline Friendly* & 1 & 2 & 3 & 4 & 5 & 6 \\
\hline Cruel & 1 & 2 & 3 & 4 & 5 & 6 \\
\hline Dangerous & 1 & 2 & 3 & 4 & 5 & 6 \\
\hline Addict & 1 & 2 & 3 & 4 & 5 & 6 \\
\hline Alcohol User & 1 & 2 & 3 & 4 & 5 & 6 \\
\hline Kind* & 1 & 2 & 3 & 4 & 5 & 6 \\
\hline Violent & 1 & 2 & 3 & 4 & 5 & 6 \\
\hline Anti-West & 1 & 2 & 3 & 4 & 5 & 6 \\
\hline Terrorist & 1 & 2 & 3 & 4 & 5 & 6 \\
\hline Aggressive & 1 & 2 & 3 & 4 & 5 & 6 \\
\hline Criminal & 1 & 2 & 3 & 4 & 5 & 6 \\
\hline Phony & 1 & 2 & 3 & 4 & 5 & 6 \\
\hline
\end{tabular}




\section{Appendix F}

Attribution Questionnaire

\section{Defendant Internality}

More due to his personality

More due to the environment

To what extent is the crime due to his personality or

to the environment?

Reflects the defendant

Reflects society

To what extent does

1

2

3

4

5

6

$\begin{array}{lll}7 & 8 & 9\end{array}$

him or society?

More due to personal reasons

More due to societal reasons

To what extent is the 1 2 3

4

5

6

$\begin{array}{ll}7 & 8\end{array}$ crime due to personal or societal reasons?

\section{Defendant Stability}

Extremely unlikely

Extremely likely

$\begin{aligned} & \text { What is the likelihood } \\ & \text { What this defendant }\end{aligned}$
$\begin{aligned} & \text { would commit the } \\ & \text { same crime again in } \\ & \text { the future? }\end{aligned}$
$\begin{aligned} & \text { What is the likelihood } \\ & \text { that this defendant }\end{aligned}$
$\begin{aligned} & \text { would commit any } \\ & \text { crime in the future? }\end{aligned}$
$\begin{aligned} & \text { What is the likelihood } \\ & \text { that this defendant } \\ & \text { will reform and not } \\ & \text { commit any crimes in } \\ & \text { the future? }\end{aligned}$




\section{Defendant Responsibility}

Not at all Very much

\begin{tabular}{|c|c|c|c|c|c|c|c|c|}
\hline $\begin{array}{l}\text { Did the defendant } \\
\text { intend to commit the } \\
\text { crime? }\end{array}$ & 1 & 2 & 3 & 4 & 5 & 6 & 7 & 8 \\
\hline $\begin{array}{l}\text { Was the defendant } \\
\text { able to foresee the } \\
\text { outcome of his } \\
\text { behavior? }\end{array}$ & 1 & 2 & 3 & 4 & 5 & 6 & 7 & 8 \\
\hline $\begin{array}{l}\text { How responsible is } \\
\text { the defendant for his } \\
\text { behavior? }\end{array}$ & 1 & 2 & 3 & 4 & 5 & 6 & 7 & 8 \\
\hline
\end{tabular}




\section{Appendix G}

1. What was the defendant's race?
a. White
b. Black
c. Indigenous
d. Chinese
e. Filipino
f. Latin American
g. Arab
h. South Asian
i. South-east Asian
j. West Asian
k. Korean
1. Japanese
m. I don't know/can't remember

2. What was the defendant's name?
a. Jake Holden
b. Ray Easton
c. Will Borden
d. Thomas Williams
e. Samir Bahar
f. Mike Thompson
g. I don't know/can't remember

3. What was the defendant's religious affiliation?
a. Christian
b. Muslim
c. Jewish
d. Buddhist
e. Not mentioned
f. I don't know/can't remember

4. What was the defendant charged with?
a. Advocating or Promotion the Commission of Terrorism Offences
b. Public Incitement of Hatred
c. Willful Promotion of Hatred
d. I don't know/can't remember 


\section{Appendix H}

\section{Informed Consent}

The purpose of an informed consent is to make sure that you understand the purpose of the study and your involvement as a participant. The informed consent must include enough information regarding the study for you to be able to make a well-informed decision regarding whether or not you would like to partake in the study.

Present Study: Jury Decision Making in a Criminal Trial

Research Personnel: This study is being conducted by Master's student Andrew Woodard from the Department of Psychology (AndrewWoodard@cmail.carleton.ca), under the supervision of Dr. Evelyn Maeder from the Institute of Criminology and Criminal Justice/Department of Psychology at Carleton University (evelyn.maeder@carleton.ca).

Concerns: Should you have any ethical concerns with the study, please contact Dr. Andy Adler, Chair, Carleton University Research Ethics Board-B (by phone: 613-520-2600 ext. 4085 or by email: ethics@carleton.ca).

Purpose: This is a study to evaluate how people process trial information.

Task Requirements: You have been asked to participate in a study concerning how people process trial information. During this study, you are asked to read a real trial transcript involving an Advocating/Promoting Commission of Terrorism Offences charge. You are asked to read the entire transcript and then determine a verdict as well as answer several other opinion-related questions. This study will take you approximately 20-30 minutes to complete. You will be awarded compensation based on time spent for completion. As per Qualtrics regulations, participants will not be compensated if they fail the required manipulation checks.

Eligibility: Prior to reading the trial transcript, participants will be screened to ensure that they are eligible to serve on a Canadian jury (Canadian citizen, at least 18 years old, fluent in English, and have no indictable offenses). Participants who do not complete the survey due to not meeting eligibility criteria will still receive partial incentive.

Potential Risk/Discomfort: You will also be asked to answer questions regarding your attitudes about certain sensitive topics and you may become uncomfortable with the nature of the questions. At any time, you may skip questions or discontinue your involvement in this study. Choosing to withdraw will not affect your standing in the Qualtrics database.

Anonymity/Confidentiality: The data collected in this experiment are strictly confidential and anonymous. No identifying information will be collected at any time. We collect data through the software Qualtrics, which uses servers with multiple layers of security to protect the privacy of the data (e.g., encrypted websites and pass-word protected storage). Please note that Qualtrics is hosted by a server located in the USA, and is subject to U.S. privacy laws. Once the study is completed, the data will be downloaded upon and stored on password-protected lab computers in a locked lab and kept indefinitely. The Qualtrics database will be deleted. The information in this 
database cannot be matched to your responses. All the information you provide will be strictly confidential and anonymous. These data may be shared with trusted colleagues and with competent professionals and may be used for research publication and/or teaching purposes.

Right to withdraw data: In addition, you may refrain from answering any questions on the questionnaire if you are uncomfortable or otherwise do not want to. At any point in the study, you may withdraw and this will not affect your status with Qualtrics. At the end of the study, you will be asked if you would like to withdraw your data from the study and will have the option of doing so immediately if you should so wish. Once you leave the survey, your data cannot be withdrawn at a future date.

This study has been reviewed and cleared by the Carleton University Research Ethics BoardB (CUREB-B Clearance \#106875), Date of Ethics Expiry - June 30th, 2018 


\section{Appendix I}

\section{Debriefing Form}

What are we trying to learn in this research and how was this study designed?

The primary purpose of this study is to examine jurors' perceptions of the applicability of Canadian anti-terrorism law in the courtroom, with defendants of differing races and religions. The trial transcript that you read was not an actual trial, but was rather fabricated for this line of research. None of the individuals in the photographs which you viewed were actually involved in such a case, to our knowledge. We systematically changed the defendant race (White, Black, Arab), and the defendant religion (Christian, Muslim, Undisclosed).

\section{Why was the use of deception necessary?}

Deception occurs when information is intentionally omitted or when misinformation is intentionally delivered. In our study, we were not able to inform you of the specific purpose of the study, nor of the specific nature of the questions which we asked you to answer prior to your completion of the study. The effect of race/religion on juror decision-making may be an unconscious one and is an effect created through societal norms and values. Informing participants about the true purpose of our study would inevitably change how they viewed the defendant on the basis of race or religion. Deception was also employed in order to avoid an effect of social desirability, which is a phenomenon where individuals modify their answers to fit with what they perceive to be socially acceptable. Please be aware that in the event that you are uncomfortable you may withdraw without penalty.

\section{What are our hypotheses and predictions?}

Previous research has demonstrated negative cultural stereotypes regarding Arab Canadians, and these stereotypes might influence juror decision-making (Ghavami, 2013; Jones \& Kaplan, 2003). As such, we predict that Arab Muslim Canadians will be perceived as more guilty than White Canadians.

In our view, it is important to identify racial and religious stereotypes in general, and specifically in a legal context so that we can identify how these stereotypes might affect specific racial and religious groups, and potentially work to reduce these stereotypes.

\section{Where can I learn more?}

Jones, C. S., \& Kaplan, M. F. (2003). The effects of racially stereotypical crimes on juror decision-making and information-processing strategies. Basic and Applied Social Psychology, 25, 1-13.

Devine, D.J., (2012). Jury Decision Making: The State of the Science. New York: New York University Press.

Ghavami, Negin. (2013). An Intersectional Analysis of Gender and Ethnic Stereotypes: Testing Three Hypotheses. Psychology of women quarterly. (37)1. p.113 - 127. 


\section{What if I have questions later?}

If you have any remaining questions or concerns, please feel free to contact Andrew Woodard (Department of Psychology, at AndrewWoodard@cmail.carleton.ca), or Dr. Evelyn Maeder (Institute of Criminology and Criminal Justice, at 613-520-2600 ext.

2421 evelyn.maeder@carleton.ca). Should you have any ethical concerns with the study, please contact Dr. Andy Adler, Chair, Carleton University Research Ethics Board-B (by phone: 613520-2600 ext. 4085 or by email: ethics@carleton.ca).

Is there anything I can do if I found this experiment emotionally draining?

Yes. It is natural to feel uncomfortable when considering the impact of racial stereotypes, particularly when your race or religion is targeted. If this experiment has caused you any distress that persists for more than 5 minutes, please contact The Mental Health Helpline 1-800-273-8255 or visit http://www.mentalhealthhelpline.ca. These resources will provide you the opportunity to discuss your feelings and experiences regarding racial stereotyping.

\section{Consent-to-keep-data Form}

The purpose of a consent-to-keep-data form is to make sure that you are able to make an informed decision regarding whether or not you would like your data included in this study. We have included this form after explaining the true purpose of our study and the reasons for which deception was necessary. This form is meant to give you an opportunity to withdraw your data from the study, now that you are aware of its purpose. In the event that you wish to withdraw your data, it will be destroyed. After this point, it will not be possible to withdraw your data from the study.

By answering this form, you indicate that you understand that you were not informed of the true purpose of this study prior to completing your participation in the study, and that you understand the reasons regarding the necessity of the use of deception in this study.

This study has been reviewed and cleared by the Carleton University Research Ethics BoardB (CUREB-B Clearance \#106875), Date of Ethics Expiry - June 30th, 2018

Please indicate whether you do / do not continue to consent to the use of your data. 